\title{
INDIVIDUAL-BASED MODEL OF YELLOW PERCH AND WALLEYE POPULATIONS IN ONEIDA LAKE
}

\author{
Kenneth A. Rose, ${ }^{1,5}$ Edward S. Rutherford, ${ }^{2}$ Dennis S. McDermot, ${ }^{3}$ John L. Forney, ${ }^{4}$ And \\ EdWARD L. MILls ${ }^{4}$ \\ ${ }^{1}$ Environmental Sciences Division, Post Office Box 2008, Oak Ridge National Laboratory, \\ Oak Ridge, Tennessee 37831-6036 USA \\ ${ }^{2}$ Institute for Fisheries Research, University of Michigan, Ann Arbor, Michigan 48109-1084 USA \\ ${ }^{3}$ Department of Ecology and Evolutionary Biology, University of Tennessee, Knoxville, Tennessee 37796-1300 USA \\ ${ }^{4}$ Cornell University Biological Station, 900 Shackelton Point Road, Bridgeport, New York 13030-9750 USA
}

\begin{abstract}
Predator-prey dynamics and density dependence are fundamental issues in ecology. We use a detailed, individual-based model of walleye and yellow perch to investigate the effects of alternative prey and compensatory responses on predator and prey population dynamics. Our analyses focus on the numerical and developmental responses of the predator, rather than the traditional emphasis on functional responses. The extensive database for Oneida Lake, New York, USA was used to configure the model and ensure its realism. The model follows the daily growth, mortality, and spawning of individuals of each species through their lifetime. Three ecologically distinct periods in the history of Oneida Lake were simulated: baseline, high mayfly densities, and high forage fish densities. Mayflies and forage fish act as alternative prey for walleye. For model corroboration, the three periods were simulated sequentially as they occurred in Oneida Lake. Model predictions of abundances, size at age, and growth and survival rates compared favorably with Oneida Lake data. Three hypotheses suggested by the data were evaluated: alternative prey stabilizes yellow perch and walleye populations; alternative prey increases yellow perch and walleye recruitment; and density-dependent growth and survival compensate for changes in young-of-the-year mortality. Model simulations were performed under increased mayfly densities, increased forage fish densities, and increased egg mortality rates. Predicted recruitment and population stability depended on the magnitude of increased walleye prey and differed between mayflies and forage fish. Compensation was driven by density-dependent growth, resulting in younger age at maturation and increased fecundity. We compare our results using a detailed, size-structured model capable of numerical and developmental responses of predators to results from classical predator-prey theory. Weaknesses in the current version of the individual-based model and knowledge gaps that require additional empirical data collection are also discussed.
\end{abstract}

Key words: compensation; density dependence; fish; individual-based; population dynamics; predator-prey; recruitment; simulation model; stability; walleye; yellow perch.

\section{INTRODUCTION}

The dynamics between predators and prey is one of the dominant themes in ecology (Berryman 1992). Much experimental and theoretical work has been devoted to studying how predators influence the stability of their prey populations (Murdoch and Oaten 1975, Oaten and Murdoch 1975a, Beddington et al. 1976, Murdoch and Bence 1987). Much of this work has been on the functional responses of predators and the effects of alternative prey. Most of the models used to determine the effects of predators on prey are equilibrium models (e.g., Murdoch and Oaten 1975) or dynamic Lotka-Volterra-like models (e.g., Oaten and Murdoch

Manuscript received 17 February 1998; revised 9 June 1998; accepted 18 June 1998.

${ }^{5}$ Present address: Coastal Fisheries Institute, Wetlands Resources Building, Louisiana State University, Baton Rouge, Louisiana 70803-7503 USA. 1975b, Hastings and Powell 1991, Berryman 1992). These models have been used to evaluate how different functional response curves and alternative prey could stabilize prey dynamics in two- and three-trophic-level systems (Murdoch and Oaten 1975, Matsuda et al. 1986, Prajneshu and Holgate 1987, Hastings and Powell 1991). Far less attention has been paid to the numerical and developmental responses of predators and their effects on prey populations.

Density-dependent reproduction, growth, and survival are also critical issues in ecology because of their importance to understanding population dynamics (Murray 1994). Yet, detecting and quantifying density dependence in field situations is difficult (Eberhardt 1970, Slade 1977, den Boer and Reddingius 1989), and its formulation in models is often at the root of controversy (Barnthouse et al. 1984). In the context of arguing that looking for density dependence does not justify long-term studies, Krebs (1991) even goes so 
far as to characterize the density-dependent paradigm as bankrupt. While this is an overstatement, the strong opinion expressed illustrates the importance and controversy of density dependence. In response to the problems associated with quantifying density dependence, alternative concepts have been proposed, such as density-vague (Strong 1986) and population limitation (Murray 1994). While the existence of density dependence is not disputed, there is much disagreement as to the appropriate way to study it and represent it in population models.

The well-studied yellow perch-walleye populations of Oneida Lake (Mills et al. 1987, Mills and Forney 1988) provide a long-term database for examining predator-prey dynamics and density dependence. We used the extensive database to develop, calibrate, and corroborate an individual-based model of yellow perch-walleye dynamics. Model simulations were performed to examine the effects of alternative prey for walleye on prey and predator recruitment and stability, and to quantify density-dependent responses of both species to changes in their egg mortality rates.

The model we describe offers a different approach to examining predator-prey interactions than the equilibrium or simple predator-prey models previously used. Our individual-based model includes size structure within each population, is much richer in biological detail, and represents a more complex and realistic predator-prey interaction than most previous models. Reproduction, growth, and mortality of fish, and many other organisms, are believed to be heavily influenced by size and size-based encounters (Ebenman and Persson 1988, Miller et al. 1988, Beyer 1989, Pepin and Myers 1991). Representing the influence of size and size-based encounters can be difficult in aggregate models, but is relatively straightforward with an individual-based approach. Predator-prey interactions are also more realistic in our model than in the usual, simple predator-prey models. We represent yellow perch as one of three food sources for walleye, and we simulate asymmetric competition and predation between yellow perch and walleye. The asymmetry arises because larvae of both species compete for zooplankton, whereas adult walleye consume young yellow perch (Persson 1988). Yellow perch and walleye also provide an excellent case study of density dependence. Studies by Forney $(1965,1971,1974,1976,1977 a)$, and others (Tarby 1974, Neilson 1980, Serns 1982, Muth and Wolfert 1986, Buijse and Houthuijzen 1992) indicate these species (and congeneric pikeperch Stizostedion lucioperca and European perch Perca fluviatilis) show strong compensatory responses in growth and age at maturity to changes in mortality.

Our modeling results are of theoretical and practical interest. Oneida Lake provides an opportunity to configure a detailed, individual-based model of a predatorprey system. We then use the model to examine the long-term (multigenerational) effects of alternative prey and density dependence on predator-prey dynamics. Our results are also of interest to resource managers. Yellow perch and walleye support important recreational and commercial fisheries and are the dominant prey and predator, respectively, in many North American temperate lakes. Understanding the effects of alternative prey on predator-prey dynamics can also be useful for understanding potential effects of introduced species. The Oneida Lake database includes past periods of high abundances of the introduced white perch Morone americana (Mills and Forney 1988), and the Oneida Lake food base is presently undergoing changes due to the recent invasion by zebra mussels.

This paper is organized into five sections. First, we briefly describe Oneida Lake and present data from three ecologically distinct periods in the lake's history: baseline, high mayfly densities, and high forage fish densities. Mayflies and forage fish act as alternative prey for walleye, potentially reducing walleye predation pressure on yellow perch. Three hypotheses, which are fundamental to population dynamics theory and suggested by the data, are stated: (1) alternative prey stabilizes the yellow perch and walleye populations, (2) alternative prey increases yellow perch and walleye recruitment, and (3) density-dependent growth and survival compensate for changes in young-of-the-year (YOY) mortality. Second, the individual-based model is documented in some detail. Model simulations for calibration, corroboration, and examination of the three hypotheses are described in the third section, followed by presentation of the results in the fourth section. Finally, we discuss how our results relate to general predator-prey theory, weaknesses in the current version of the individual-based model, and knowledge gaps that require additional empirical data collection.

\section{ONEIDA LAKE}

\section{Site description}

Oneida Lake is a large $\left(207 \mathrm{~km}^{2}\right)$, eutrophic lake in central New York, with a mean depth of $6.8 \mathrm{~m}$ and a maximum depth of $16.8 \mathrm{~m}$. Except for brief periods of temperature and oxygen stratification, prevailing northwesterly winds and wind-driven currents maintain well-mixed, isothermal conditions through the summer. Much of the shoreline is exposed to vigorous wave action. Submerged plants are restricted to protected bays. Rubble or sand substrate occur in shallow areas; mud is found at depths over $4 \mathrm{~m}$. The general lack of vertical stratification and relatively small littoral zone implies that fish population dynamics in the lake could be approximated by simulating individuals within a single, well-mixed volume.

\section{Historical changes in walleye prey}

The population dynamics and trophic interactions of Oneida Lake walleye and yellow perch have been studied over the past $40 \mathrm{yr}$ (Forney 1965, 1967, 1971, 1974, 
1976, 1977a, b, c, 1978, 1980, Mills and Forney 1981, 1983, 1988, Mills et al. 1978, 1987, 1989, Tarby 1974, Tarby and Forney 1978, Neilson 1980). Recruitment of yellow perch and walleye is operationally defined in this paper as survival to October of their second year (yearlings). Yearling abundances in October, or earlier life stage abundances, are highly correlated with their subsequent abundances as adults, for both yellow perch and walleye in Oneida Lake (Forney 1971, 1976).

In most years, YOY yellow perch were the dominant prey of adult walleye; white perch (Morone americana), gizzard shad (Dorosoma cepedianum), and young walleye were of secondary importance in walleye diets (Forney 1974, Prout et al. 1990). Research indicated that yellow perch recruitment was determined by wind and temperature regimes during the egg stage, as well as by abundance, density-dependent growth, biomass of other YOY forage species, and size-selective predation on YOY and yearling perch by walleye (Forney 1971, 1974, 1977a, b, c, 1978, 1980, Tarby 1974, Clady and Hutchinson 1975, Clady 1976, Neilson 1980). Walleye recruitment seemed to be determined by fluctuations in larval abundance, abundance and size of walleye forage (principally YOY and yearling yellow perch), and walleye cannibalism (Chevalier 1973, Forney 1971, 1974, 1977a, b, c, 1978, 1980).

Major shifts in the abundance of forage available to walleye occurred during the period of record (19561988). Variation in forage caused changes in the population dynamics of both yellow perch and walleye. Three distinct periods can be defined. The "mayfly" period (1956-1969) was characterized by high densities $\left(\sim 200\right.$ individuals $\left./ \mathrm{m}^{2}\right)$ of Hexagenia limbata, which emerged during June and July. Mayflies are believed to reduce walleye predation on YOY yellow perch by serving as an alternative prey (Forney 1980). This period is characterized by strong, stable year classes of walleye and yellow perch.

The "baseline" period (1970-1978) was characterized by the absence of mayflies and relatively low abundances of white perch. Walleye-yellow perch dynamics were more tightly coupled during the baseline period, uncomplicated by high abundances of alternative prey. Walleye exhibited higher rates of cannibalism (Chevalier 1973) and predation on yellow perch, resulting in lower and more variable yellow perch and walleye recruitment (Forney 1980).

The "forage fish" period (1979-1988) was characterized by strong year classes of YOY white perch (Prout et al. 1990) or gizzard shad (Roseman et al. 1996) that complicated yellow perch-walleye interactions (Mills and Forney 1988). Forage fish can compete with YOY yellow perch for zooplankton prey (Prout et al. 1990, Roseman et al. 1996) and provide late-summer forage for adult walleye, thereby altering the distribution of predation pressure among forage fish species (Forney 1974). Counterintuitively, despite increased forage for walleye, YOY and yearling yellow perch and walleye abundances were generally low during the forage fish period. For all three periods, similar adult abundances of yellow perch and walleye were observed, with year-to-year variability lower during the mayfly and forage fish periods, compared to the baseline period.

\section{Testable hypotheses}

The historical changes in Oneida Lake provide an opportunity to examine the effects of alternative prey on yellow perch population stability and to investigate density-dependent responses (compensation) of yellow perch and walleye. We caution the reader that, while the field data can be used to broadly support the ideas of increased stability and recruitment under increased alternative prey and density-dependent compensation, the data are noisy and confounded with other factors. Peak abundances of the two alternative prey were separated in time by nine years of baseline conditions, and the life spans of both walleye and perch (10-12 yr) are roughly equal the duration of each of the mayfly, baseline, and forage fish periods. Also, before 1980, variation existed in the annual number of walleye yolk sac larvae that were stocked. Moreover, fishing size limits changed during the period of record. Thus, it is difficult to cleanly test these hypotheses using empirical information. Consequently, we use the individual-based model, developed from the historical Oneida Lake database, to evaluate the effects of alternative prey and compensation on yellow perch and walleye dynamics.

Three general hypotheses emerge from the comparison of yellow perch and walleye dynamics in Oneida Lake during the mayfly, baseline, and forage fish periods. We analyzed the historical data, with the 1977 yellow perch year-class removed, to assess the empirical support for the three hypotheses. YOY yellow perch survival was much higher in 1977 , compared to survival in the other years of the baseline period, because walleye adult abundances were extremely low and forage fish abundances were very high. We eliminated the 1977 year class to prevent its undue influence on computed mean abundances and coefficients of variation $(\mathrm{CV}=100 \times \sigma /$ mean $)$.

Hypothesis 1: “increased stability."-The presence of alternative prey (mayflies or forage fish) for walleye stabilizes (i.e., lowers interannual variation) the population dynamics of yellow perch and walleye (Table 1). For all life stages of walleye and for YOY yellow perch, coefficients of variation of annual abundances during the mayfly and forage fish periods were either lower than or similar to those during baseline conditions. However, CVs of yellow perch recruitment for the mayfly and forage fish periods, and of adult yellow perch abundances for the forage fish period, were higher than CVs under baseline conditions.

Hypothesis 2: "higher recruitment."-Increases in mayfly and forage fish densities cause higher recruitment of yellow perch and walleye. Empirical evidence 
TABLE 1. Coefficients of variation, means, and ratios of yellow perch and walleye abundances in Oneida Lake for the mayfly (1956-1969), baseline (1970-1978), and forage fish (19791988) periods.

\begin{tabular}{|c|c|c|c|c|c|c|}
\hline \multirow[b]{2}{*}{ Hypothesis (in bold) and data } & \multicolumn{3}{|c|}{ Yellow perch } & \multicolumn{3}{|c|}{ Walleye } \\
\hline & B & M & FF & B & M & FF \\
\hline \multicolumn{7}{|l|}{ Hypothesis 1: increased stability } \\
\hline \multicolumn{7}{|l|}{ Coefficient of variation (\%) } \\
\hline YOY (August) & 99 & 39 & 75 & 66 & 50 & 63 \\
\hline YOY (October) & 148 & 82 & 105 & 141 & 64 & 79 \\
\hline Recruitment & 34 & 89 & 43 & 502 & 189 & 426 \\
\hline Adults & 36 & 22 & 54 & 35 & 15 & 33 \\
\hline \multicolumn{7}{|l|}{ Hypothesis 2: higher recruitment } \\
\hline \multicolumn{7}{|l|}{ No. individuals/ha } \\
\hline YOY (October) & 1780 & 2740 & 920 & 40 & 89 & 22 \\
\hline Recruitment & 19 & 144 & 31 & 9.0 & 16 & 7.6 \\
\hline \multicolumn{7}{|l|}{ Hypothesis 3: compensation } \\
\hline \multicolumn{7}{|l|}{ Ratio to baseline } \\
\hline YOY (August) & $\ldots$ & 1.9 & 0.76 & $\ldots$ & 2.7 & 0.59 \\
\hline YOY (October) & $\ldots$ & 1.5 & 0.52 & $\ldots$ & 2.2 & 0.55 \\
\hline Recruitment & $\ldots$ & 7.6 & 1.6 & $\ldots$ & 1.8 & 0.84 \\
\hline Age-3 (May) & $\ldots$ & 1.2 & 0.88 & $\ldots$ & $\ldots$ & $\ldots$ \\
\hline Age-4 (May) & $\ldots$ & $\ldots$ & $\ldots$ & $\ldots$ & 1.4 & 1.1 \\
\hline Adults & $\cdots$ & 1.2 & 1.1 & $\cdots$ & 1.2 & 1.1 \\
\hline
\end{tabular}

Notes: These data were extracted from the Oneida Lake database as empirical support for the three hypotheses evaluated with the individual-based model: increased stability, increased recruitment, and compensation. Data were analyzed with the exceptionally high 1977 yellow perch year class removed. B, baseline period; M, mayfly period; FF, forage fish period.

for higher recruitment under alternative prey is mixed (Table 1). Average abundances of YOY yellow perch and walleye in October, and recruitment of yellow perch and walleye, were highest under increased mayflies; however, YOY abundances in October of both species were lowest under increased forage fish, and walleye recruitment under increased forage fish and baseline were similar. Although the empirical evidence for increased recruitment under increased forage fish is weak, we formulate the hypothesis assuming that more alternative prey for walleye should benefit yellow perch and walleye recruitment, due to reduced walleye predation pressure on yellow perch and reduced walleye cannibalism.

Hypothesis 3: “compensation.”-Density-dependent survival and growth offsets changes in YOY mortality. Average adult abundances for the mayfly, forage fish, and baseline periods are roughly similar for yellow perch $(135,124$, and 114 individuals/ha) and for walleye (34.6, 31.7, and 29.2 individuals/ha), despite greater differences in their YOY abundances and recruitment. Ratios of average abundances at various life stages between mayfly and baseline period values and between forage fish and baseline period values tend to be closest to 1.0 for adults (Table 1).

\section{MOdel Description}

\section{Model overview}

The model begins with spawning of individual females and simulates growth and mortality of each female's progeny as they develop through successive life stages (egg, yolk sac larva, feeding larva, YOY ju- venile, yearling, and adult). The model represents daily dynamics in a single, well-mixed compartment $(260 \times$ $260 \times 6.8 \mathrm{~m}$, where the final dimension represents the depth). Model simulations are $55 \mathrm{yr}$ in duration for corroboration and $50 \mathrm{yr}$ for hypothesis evaluation. Model years are $365 \mathrm{~d}$ and begin on 10 April.

Eggs and yolk sac larvae are followed as cohorts, while larvae, juveniles, and adults are followed as individuals. Each female's spawn of eggs is followed as a cohort until first feeding. The number in each cohort and the degree of development are tracked daily. Individual fish are modeled from the larval through adult stages. A maximum age of $10 \mathrm{yr}$ is assumed for yellow perch and $12 \mathrm{yr}$ for walleye. The model keeps track of sex, length (mm, total length), mass ( $\mathrm{g}$ wet mass), age, and life stage for each individual. Environmental conditions in the compartment are daily average water temperature and average densities of prey. An earlier version of the model was described in Rose et al. (1996). Values of environmental variables and model parameters not attributed to a literature citation are based on the data of the authors (J. L. Forney and E. L. Mills, unpublished data). Environmental variables and parameter values were determined from the available Oneida Lake data regardless of the period during which the data were collected. Using data from different time periods was justified because either environmental variables and parameter values did not differ among periods, or data were inadequate to determine periodspecific values. Two variables that exhibited obvious differences among time periods were mayfly and forage fish densities; period-specific values of these variables were used in model simulations. 


\section{Daily temperature}

Daily temperatures $\left(T,{ }^{\circ} \mathrm{C}\right)$ for $365 \mathrm{~d}$ beginning on 10 April are generated from fitting the observed average daily temperatures from 1968-1975 measured at $2 \mathrm{~m}$ depth in Oneida Lake to the following regression equation:

$T=11.91-11.76 \sin (2 \pi \times$ day $\times 0.003+3.81)$

where "day" indicates the calendar day $(1=1$ January, $2=2$ January, . . .), and the argument of the sine function is in radians. Lake temperature rises from $5^{\circ} \mathrm{C}$ on 10 April to a maximum of $23-24^{\circ} \mathrm{C}$ from mid-Julymid-August, and then declines to a minimum value of $1-2^{\circ} \mathrm{C}$ over winter.

\section{Spawning}

Adults are evaluated for spawning on 10 April of each year. A female adult is mature if a generated random number is less than the fraction mature for her length. Fraction mature by length, $H(L)$, for yellow perch is based on Oneida Lake data (J. L. Forney and E. L. Mills, unpublished data) that yields the following relationship:

$$
H(L)=\frac{0.98}{1.0+e^{21.2-0.11 L}}
$$

where $L$ is length $(\mathrm{mm})$. Fraction mature by length for walleye is given by

$$
H(L)=\frac{1.27}{1.0+e^{11.4-0.03 L}}-0.2 .
$$

Eq. 3 is based on fitting a function to values of the fraction of females mature (as determined by length), intermediate to those observed for fast and slow walleye growth periods in Lake Erie (Muth and Wolfert 1986). For typical lengths at age, $57 \%$ of age- 3 yellow perch and $35 \%$ of age- 5 walleye are mature.

All mature females alive on 10 April are assumed to spawn (i.e., no mortality during the spawning season). Fecundity ( $F$, no. eggs/female) is related to female mass ( $W$, g wet mass) as follows:

$$
F=a_{\mathrm{F}} W-b_{\mathrm{F}}
$$

where $a_{\mathrm{F}}=183.0 \mathrm{eggs} / \mathrm{g}$ and $b_{\mathrm{F}}=3658.0 \mathrm{eggs} / \mathrm{female}$ for yellow perch and $a_{\mathrm{F}}=70.6 \mathrm{eggs} / \mathrm{g}$ and $b_{\mathrm{F}}=7900.0$ eggs/female for walleye (Forney 1978). Females spawn on the first day that the simulated temperature exceeds their assigned spawning temperature. Temperature of spawning is generated for each yellow perch female from a uniform distribution with $7^{\circ} \mathrm{C} \leq T \leq 11^{\circ} \mathrm{C}$ (Thorpe 1977, Craig 1987). Temperature of spawning for each walleye female is generated from a triangular distribution with $4^{\circ} \mathrm{C} \leq T \leq 13^{\circ} \mathrm{C}$ and mode $=7^{\circ} \mathrm{C}$ (Colby et al. 1979). Spawning temperatures are assigned to each female annually; females do not keep the same spawning temperature year after year. Onehalf of the average biomass of spawned eggs per in- dividual (egg masses are $2.3 \mathrm{mg}$ for yellow perch and $3.8 \mathrm{mg}$ for walleye) is subtracted from each mature female and male individual. We adjust masses of males and females because mean lengths at age were $\sim 25$ $\mathrm{mm}$ longer for females than males in Oneida Lake (Forney 1965). Removing egg biomass from only the female spawners would result in smaller females than males in model simulations.

\section{Eggs and yolk sac larvae}

Each female's spawn of eggs is followed as a cohort until first feeding. Day of hatching and day of first feeding are determined separately for each cohort by accumulating daily fractional development rates until the cumulative development $>1$. All larvae in each female cohort begin first feeding on the same day. Numbers of eggs or yolk sac larvae in each cohort are reduced daily by mortality.

For yellow perch, daily fractional development towards hatching $\left(\mathrm{DV}_{\mathrm{e}}\right)$ is computed each day based on temperature (Mansueti 1964, Swift 1965, Hokanson and Kleiner 1974, Treasurer 1983):

$$
\mathrm{DV}_{\mathrm{e}}=\frac{1}{145.7+2.56 T-63.8 \log _{e} T}
$$

Development from hatching to first feeding is assumed to be $3 \mathrm{~d}\left(\mathrm{DV}_{\mathrm{y}}=0.33\right)$ (Lake 1967, Hokanson and Kleiner 1974). Daily instantaneous mortality rate $(Z$, $\mathrm{d}^{-1}$ ) of eggs and yolk sac larvae is negatively related to temperature (Clady and Hutchinson 1975, Clady 1976; J. L. Forney, unpublished data):

$$
Z=0.52-0.036 T \text {. }
$$

Egg mortality rates are not permitted to be $<0.015 \mathrm{~d}^{-1}$ (which occurs at $14^{\circ} \mathrm{C}$ ), while yolk sac larvae mortality rates are truncated at $0.09 \mathrm{~d}^{-1}$ (which occurs at $12^{\circ} \mathrm{C}$ ). The truncation values were based on minimum observed mortality rates in Oneida Lake, and were chosen to result in realistic egg-to-first-feeder survival. Average simulated egg-to-first-feeder survival is $\sim 8 \%$, compared to an average observed survival rate in Oneida Lake of 7\% (range of 1.4-16.0\%) for 1965-1977 (Tarby and Forney 1978).

For walleye, daily fractional development toward hatching is estimated from measurements of incubation duration at three temperatures (McElman and Balon 1979, Li and Mathias 1982):

$$
\mathrm{DV}_{\mathrm{e}}=\frac{1}{57.1 e^{-(T / 18.9)}-15.4}
$$

Development rate from hatching to first feeding $\left(\mathrm{DV}_{\mathrm{y}}\right)$ is also assumed to be temperature dependent (McElman and Balon 1979, Li and Mathias 1982, Hokanson and Lien 1986):

$$
\mathrm{DV}_{\mathrm{y}}=\frac{1}{8.79-9.62 \times 10^{-5} T^{3.61}}
$$

Mortality of eggs and yolk sac larvae is set to $0.15 \mathrm{~d}^{-1}$. 
TABLE 2. Values of bioenergetics parameters used in the individual-based model.

\begin{tabular}{|c|c|c|c|c|}
\hline \multirow[b]{2}{*}{ Parameter } & \multicolumn{2}{|c|}{ Yellow perch } & \multicolumn{2}{|c|}{ Walleye } \\
\hline & YOY & $(\geq$ age- 1$)$ & $<43 \mathrm{~mm}$ & $\geq 43 \mathrm{~mm}$ \\
\hline \multicolumn{5}{|c|}{ Maximum consumption } \\
\hline $\begin{array}{l}a_{c} \\
b_{c} \\
T_{0}\left({ }^{\circ} \mathrm{C}\right) \\
T_{\mathrm{m}}\left({ }^{\circ} \mathrm{C}\right) \\
\Theta\left(\left[{ }^{\circ} \mathrm{C}\right]^{-1}\right)\end{array}$ & $\begin{array}{l}0.51 \\
-0.42 \\
29 \\
32 \\
2.3\end{array}$ & $\begin{array}{l}0.25 \\
-0.27 \\
23 \\
28 \\
2.3\end{array}$ & $\begin{array}{l}0.45 \\
-0.27 \\
25 \\
28 \\
2.3\end{array}$ & $\begin{array}{l}0.25 \\
-0.27 \\
22 \\
28 \\
2.3\end{array}$ \\
\hline \multicolumn{5}{|l|}{ Metabolism } \\
\hline $\begin{array}{l}a_{r} \\
b_{r} \\
T_{0}\left({ }^{\circ} \mathrm{C}\right) \\
T_{\mathrm{m}}\left({ }^{\circ} \mathrm{C}\right) \\
\Theta\left(\left[{ }^{\circ} \mathrm{C}\right]^{-1}\right) \\
\mathrm{ACT}\end{array}$ & $\begin{array}{l}0.035 \\
-0.20 \\
32 \\
35 \\
2.1 \\
4.4\end{array}$ & $\begin{array}{l}0.035 \\
-0.20 \\
28 \\
33 \\
2.1 \\
1.0\end{array}$ & $\begin{array}{l}0.056 \\
-0.22 \\
27 \\
32 \\
2.1 \\
3.0\end{array}$ & $\begin{array}{l}0.00261 \\
-0.15 \\
\ldots \\
\ldots \\
\ldots \\
2.0\end{array}$ \\
\hline \multicolumn{5}{|c|}{ Egestion, excretion, and SDA } \\
\hline$\kappa_{\mathrm{e}}$ & 0.43 & 0.43 & 0.43 & 0.36 \\
\hline
\end{tabular}

Notes: Yellow perch values are based on Post (1990), and walleye values are based on Madon and Culver (1993). Bioenergetics switches from YOY to adult parameter values at the yearling stage for yellow perch and at $43 \mathrm{~mm}$ length for walleye. For walleye $\geq 43 \mathrm{~mm}$, we follow Fox's (1991) recommendation and use standard metabolism from Minton and McLean (1982) and an activity multiplier of 2.0. Original units of Minton and McLean (1982) were converted to $\mathrm{g} \cdot \mathrm{g}^{-1} \cdot \mathrm{d}^{-1}$ assuming $3.24 \mathrm{cal} / \mathrm{mg}$ oxygen and $1700 \mathrm{cal} / \mathrm{g}$ wet mass. Units of $a$ and $b$ are linked through their exponential relationship (Eqs. 11, 14, and 15).

Forney (1978) reported a walleye egg ( $\leq 9 \mathrm{~mm})$ mortality rate in Oneida Lake of $\sim 0.18 \mathrm{~d}^{-1}$ averaged over all years, and a rate of $0.24 \mathrm{~d}^{-1}$ averaged over the $3 \mathrm{yr}$ without walleye stocking of yolk sac larvae.

\section{Feeding life stages: development and age}

Development during YOY life stages is based on length. Yearlings and adults are promoted to the next age class annually (every 10 April). Total length ( $L$, $\mathrm{mm}$ ) is obtained from mass ( $W$, g wet mass) using length-mass relationships of the following form:

$$
L=a_{L} W^{b_{L}}
$$

where $a_{L}=45.9$ and $b_{L}=0.33$ for YOY yellow perch; $a_{L}=39.1$ and $b_{L}=0.33$ for yearling and adult yellow perch; and $a_{L}=49.0$ and $b_{L}=0.31$ for walleye (Post 1990, Madon and Culver 1993, J. L. Forney, unpublished data). Mass is partially uncoupled from length; length is only allowed to increase. On days of mass gain, length is increased only after mass has recovered to the mass associated with its length according to the length-mass relationship.

All first-feeding larvae are assigned identical initial lengths and masses: $6.6 \mathrm{~mm}, 0.0028 \mathrm{~g}$ for yellow perch (Mansueti 1964) and $9 \mathrm{~mm}, 0.0042 \mathrm{~g}$ for walleye (Houde 1969, Johnston et al. 1992). Length at metamorphosis is assumed to be $20 \mathrm{~mm}$ for yellow perch (Mansueti 1964) and for walleye (McElman and Balon 1979, Mathias and Li 1982). Upon reaching the adult stage (age-2), individuals are assigned a sex based on a 1:1 male-to-female ratio. Sex ratios of yellow perch and walleye were approximately 1:1 in Oneida Lake. Age in the model is based on birthdays taking place on 10
April of each year. Thus, an age- 4 model individual on 20 May has lived $4 \mathrm{yr}$ and $40 \mathrm{~d}$.

\section{Feeding life stages: growth}

Daily growth of each feeding individual is represented by the difference (discrete time) form of a bioenergetics equation:

$$
W_{t}=W_{t-1}+\left(p C_{\max }-E-R_{\mathrm{tot}}\right) W_{t-1}
$$

where $C_{\max }$ is maximum consumption rate, $p$ is the proportion of $C_{\max }$ realized, $E$ represents the egestion rate, excretion rate, and specific dynamic action (SDA) losses, and $R_{\text {tot }}$ is the total metabolic rate. All rates are $\mathrm{g} \cdot \mathrm{g}^{-1} \cdot \mathrm{d}^{-1}$ in wet mass.

Daily growth is determined each day. First, $C_{\max }$ and $R_{\text {tot }}$ are computed based on yesterday's fish mass and today's water temperature. Water temperature is a driving variable that varies daily. Next, $p$ is determined by a Type II functional response relationship. The proportion $p$ depends on the densities of each prey type, the vulnerability of each prey type to the predator, and the half-saturation constants that govern the amount of each prey type eaten. For each individual, we loop over all possible prey types to determine the total biomass and the number of each prey type eaten by the predator. Having determined consumption $\left(p \times C_{\max }\right)$, we then compute $E$ as a constant fraction of consumption and determine the individual's new mass for today. Values of parameters that determine $C_{\text {max }}, R_{\text {tot }}$, and $E$ are taken from previously published bioenergetics models (Table 2 ). Values of the many parameters related to the functional response relationship are specified from diet and other data. The only calibrated parameters in growth 
are the half-saturation parameters of the functional response relationship.

Maximum consumption.-Maximum consumption $\left(C_{\max }\right)$ depends on an individual's mass and water temperature in the following manner:

$$
C_{\max }=a_{\mathrm{c}} W^{b_{\mathrm{c}}} F(T) .
$$

The temperature adjustment to maximum consumption, $F(T)$, is a slowly rising function that reaches 1.0 at the assigned optimal temperature $\left(T_{0}\right.$ in Table 2$)$ and then drops to zero at the maximum temperature $\left(T_{\mathrm{m}}\right.$ in Table 2) (Hewett and Johnson 1992). The rate of rise of $F(T)$ is determined by the parameter $\theta$ in Table 2, which mimics a $Q_{10}$ multiplier. For YOY walleye eating fish prey, $C_{\max }$ is set to twice $C_{\max }$ from Eq. 11 to allow YOY walleye to eat fish prey. Fish prey first vulnerable to YOY walleye, based on their ratio of lengths, typically have masses $1-3 \times$ the $C_{\max }$ values of the walleye.

Egestion, excretion, and SDA.-Previously published bioenergetics models of walleye and yellow perch expressed egestion, excretion, and SDA losses as a constant fraction of consumption rate. For simplicity, we combine these individual terms into a single term $E$ :

$$
E=K_{\mathrm{e}} C_{\mathrm{r}} .
$$

Values of $K_{\mathrm{e}}$ are 0.36 for adult walleye and 0.43 for YOY walleye and all stages of yellow perch (Table 2).

Metabolism.-Metabolic losses $\left(R_{\text {tot }}\right)$ are determined as standard metabolism $\left(R_{\mathrm{s}}\right)$, which depends on an individual's mass and water temperature, multiplied by an activity multiplier (ACT). The activity multiplier is assumed to apply for the 24-h day. For all life stages of yellow perch and for walleye $<43 \mathrm{~mm}$,

$$
\begin{aligned}
R_{\mathrm{tot}} & =R_{\mathrm{s}} \times \mathrm{ACT} \\
R_{\mathrm{s}} & =a_{\mathrm{r}} W^{b_{\mathrm{r}}} F(T) .
\end{aligned}
$$

For walleye $\geq 43 \mathrm{~mm}$ a slightly different formulation for standard metabolism is used (see Fox 1991):

$$
\begin{aligned}
& R_{\mathrm{s}}=a_{\mathrm{r}} W^{b_{\mathrm{r}}} 10^{0.03 T} . \\
& \text { Computation of } p
\end{aligned}
$$

Values of $p$ are determined for each individual as realized consumption $\left(C_{\mathrm{r}}\right)$ divided by $C_{\max }$. Realized consumption $\left(C_{\mathrm{r}}\right)$ is based on a Type II functional response relationship (Holling 1965), with available prey types dependent on species, life stage, and/or (predator length): (prey length) ratios.

Realized consumption.-Realized consumption of prey by each individual depends on prey densities, vulnerability of each prey type to the individual predator, and half-saturation constants governing rate of predator saturation. A Type II functional response equation for multiple prey types is used to compute daily consumption of each individual predator $\left(C_{\mathrm{r}}, \mathrm{g} / \mathrm{d}\right)$ and the consumption of each prey type $j\left(C_{j}, \mathrm{~g} / \mathrm{d}\right)$ :

$$
\begin{aligned}
& C_{\mathrm{r}}=\sum_{j=1}^{n} C_{j} \\
& C_{j}=\frac{C_{\max } W_{i}\left(\mathrm{PD}_{i j}^{\mathrm{V}} / K_{i j}\right)}{1+\sum_{k=1}^{n}\left(\mathrm{PD}_{i k}^{\mathrm{V}} / K_{i k}\right)}
\end{aligned}
$$

where $C_{\max }$ is the maximum daily consumption rate $\left(\mathrm{g} \cdot \mathrm{g}^{-1} \cdot \mathrm{d}^{-1}\right)$ of individual $i$ (Eq. 11), $W_{i}$ is the mass $(\mathrm{g})$ of individual $i, \mathrm{PD}_{i j}^{\mathrm{V}}$ is the density of prey type $j$ adjusted for its vulnerability to individual $i$, and $K_{i k}$ is the halfsaturation constant for individual $i$ feeding on prey type $k(k=1,2, \ldots, j, \ldots, n)$. Vulnerability-adjusted prey densities are either obtained by multiplying densities by a factor $<1$ (for zooplankton and benthos), or by determining the vulnerability of each individual fish prey item (forage fish, yellow perch, or walleye), based on its length relative to the predator length. A refuge biomass of YOY yellow perch is subtracted from the densities used in Eq. 17 to ensure that a minimal biomass of YOY yellow perch survives each year. Vulnerabilities and prey densities, sizes, and turnover rates were determined from available data, and specified values were not changed during model calibration. The $K$ values and refuge biomass of YOY yellow perch were varied during calibration to obtain agreement between observed and predicted abundances, lengths at age, and diets.

Prey types. - A total of seven prey types are represented, which encompass the dominant prey eaten by yellow perch and walleye from first feeding through the adult stage. Zooplankton, benthos, and forage fish are each represented by single species: zooplankton by small to medium-sized Daphnia, benthos by chironomid larvae, and forage fish by YOY white perch. The remaining four prey types, YOY and yearling life stages of yellow perch and walleye, are simulated as individuals in the model. Prey are expressed on a density basis as follows: no. individuals/L for zooplankton; no. individuals $/ \mathrm{m}^{2}$ for benthos; and no. individuals $/ \mathrm{m}^{3}$ for fish.

Individual masses of each prey type, and lengths for fish prey types, are either explicitly defined or simulated. Prey mass is used to convert between biomass and numbers consumed. Prey length is used for fish as prey to determine the vulnerability of an individual fish prey item to a particular predator. Mass per zooplankton is set to $8.7 \times 10^{-5} \mathrm{~g}(\sim 1.4 \mathrm{~mm})$, characteristic of Daphnia (Mills et al. 1984). Mass per benthic prey item is set to $3.81 \times 10^{-3} \mathrm{~g}(\sim 8 \mathrm{~mm})$, characteristic of chironomids in Oneida Lake (E. L. Mills, unpublished data). Lengths of individual forage fish are generated from a normal distribution with a time-dependent mean length and $\mathrm{CV}=20 \%$. Mean lengths over time are observed mean lengths of YOY white perch in Oneida Lake, multiplied by 0.75 to represent the presence of other, smaller forage fish species (e.g., gizzard shad). Mean length starts at $14 \mathrm{~mm}$ on 8 July, rises to $60 \mathrm{~mm}$ 
by 1 October, and remains at $60 \mathrm{~mm}$ until the next year class of forage fish enters on 8 July of the following year. Mass $(\mathrm{g})$ of each forage fish is obtained from its length by multiplying the mass obtained from a masslength relationship for YOY white perch $(W=3.51 \times$ $10^{-5} \times L^{2.80}$ ) by 0.75 . We multiply by 0.75 because the other species comprising forage fish (e.g., gizzard shad) tend to have less mass for a given length than white perch. Masses and lengths of individual YOY and yearling yellow perch and walleye are simulated day to day.

Prey densities.-Densities of zooplankton (no. individuals/L), benthos (no. individuals $/ \mathrm{m}^{2}$ ), and forage fish (no. individuals $/ \mathrm{m}^{3}$ ) prey types are updated daily, based on the number of prey consumed by yellow perch and walleye in combination with a modified logistic growth function:

$$
\mathrm{PD}_{j, t+1}=\mathrm{PD}_{j, t}+2 \mathrm{PD}_{j, t}\left(1-\frac{\mathrm{PD}_{j, t}}{\mathrm{PD}_{j, t}^{*}}\right) \mathrm{PT}_{j}-\mathrm{EY}_{i, t}-\mathrm{EW}_{i, t}
$$

where $\mathrm{PD}_{j, t}^{*}$ is the equilibrium density of prey type $j$ at time $t, \mathrm{PT}_{j}$ is the specified turnover rate $\left(\mathrm{d}^{-1}\right)$ of prey type $j$, and $\mathrm{EY}_{i, t}$ and $\mathrm{EW}_{i, t}$ are the densities of prey type $j$ consumed by all yellow perch and all walleye, respectively. Equilibrium densities are the maximum densities of each prey type allowed in model simulations. As simulated prey densities approach equilibrium densities, the effective turnover rate of prey approaches zero. The multiplier of 2 modifies the classical logistic growth equation so that specified turnover rates are realized when prey densities are at one-half their equilibrium densities, rather than at zero density.

Specified turnover rates $\left(\mathrm{PT}_{i}\right)$ and equilibrium densities of zooplankton, benthos, and forage fish are set to values typical for Oneida Lake. Turnover rates were set to $0.15 \mathrm{~d}^{-1}$ for zooplankton, $0.3 \mathrm{~d}^{-1}$ for benthos, and $0.07 \mathrm{~d}^{-1}$ for forage fish. Zooplankton and forage fish turnover rates are based on data for Oneida Lake (J. L. Forney and E. L. Mills, unpublished data) and general relationships between organism mass, temperature, and turnover rates (Edgar and Shaw 1995, Shuter and Ing 1997). Benthos turnover rates vary widely among species and systems, even within Chironomidae (Berg and Hellenthal 1991). We use a high value of $0.3 \mathrm{~d}^{-1}$ (see Lindegaard 1989), based on the assumption that walleye and yellow perch consumption have little effect on benthos densities. Most benthos is consumed during the relatively short periods of emergence when actual production rate would greatly exceed reported annual production rate. Equilibrium densities for zooplankton in the model are assumed to be time-dependent, based on the sum of small and medium $(<1.7$ $\mathrm{mm}$ ) Daphnia densities measured approximately weekly in Oneida Lake during the baseline period. Zooplankton densities rise from 2.5 individuals/L on 10 April, peak at 10-15 individuals/L during mid-May, and then decline to $<4$ individuals/L by early July.
Equilibrium density of benthos is set to 300 individuals $/ \mathrm{m}^{2}$, which is near the minimum summertime chironomid density reported for Oneida Lake. Chironomid densities were typically $>1000$ individuals $/ \mathrm{m}^{2}$ in June, declining to minimum monthly values of 150-500 individuals $/ \mathrm{m}^{2}$ during July-October. Forage fish equilibrium density is set to 0.027 individuals $/ \mathrm{m}^{3}$ for $9 \mathrm{July}-$ 27 October. The fish density was reduced ten-fold $\left(0.0027\right.$ individuals $\left./ \mathrm{m}^{3}\right)$ for over the winter. White perch typically spawn in late June. Densities are highly variable from year to year. Typical summer densities were $0.007-0.03$ individuals $/ \mathrm{m}^{3}$ during the baseline period in Oneida Lake. We imposed random variation on zooplankton and benthos densities experienced by each individual $( \pm 0.2$ times the mean density for yellow perch and \pm 0.8 times the mean density for walleye) to obtain realistic variation in predicted YOY and yearling yellow perch and walleye lengths.

Vulnerability factors. - Vulnerabilities vary between zero and one and depend on the predator size or the predator to prey size ratio. Vulnerability factors reflect both the predator's ability to capture prey and the predator's willingness to attack prey. For example, small predators, or predators encountering prey that are large relative to themselves, are limited by their ability to capture the prey. Alternatively, large predators, or predators encountering small prey, may ignore some prey types, because the energy gained from eating the prey is not worth the energy required to consume it. The predator-prey interactions permitted in the model, as defined by nonzero vulnerability factors, are shown in Table 3.

Prey densities or individual fish prey are multiplied by the vulnerability factor to determine their availability to a predator. For zooplankton and benthos prey types, the vulnerability factor is multiplied by the simulated density of that prey type $\left(\mathrm{PD}_{j, t}\right)$ to obtain the density seen by the predator. For modeled fish as prey, each predator sees the density of those modeled individuals vulnerable to being eaten by that predator. Forage fish are treated somewhat differently than modeled fish prey (yellow perch and walleye), because lengths are simulated as a probability distribution (i.e., individual lengths comprising the density are not known). Each predator sees the total density of forage fish; lengths of individual forage fish are then generated from a normal distribution. For yellow perch as predators, the vulnerability, $V$, is length dependent for zooplankton and either zero or one for other prey types. Vulnerability of zooplankton depends on yellow perch length until $30 \mathrm{~mm}$, after which $V=1$ :

$$
V= \begin{cases}0.02 L+0.4 & \text { for } L<30 \mathrm{~mm} \\ 1.0 & \text { for } L \geq 30 \mathrm{~mm}\end{cases}
$$

Capture success of yellow perch increases with size, reaching $100 \%$ for zooplankton for 30-mm fish (Mathias and Li 1982, Mills et al. 1989). Vulnerability of 
TABLE 3. Predator-prey interactions defined in the individual-based model by nonzero vulnerability factors. The presence of a table entry $(X)$ indicates the inclusion of the interaction in the model.

\begin{tabular}{|c|c|c|c|c|c|c|c|}
\hline \multirow[b]{3}{*}{ Prey/predator } & \multicolumn{3}{|c|}{ Yellow perch } & \multirow{2}{*}{\multicolumn{4}{|c|}{ Walleye }} \\
\hline & \multicolumn{3}{|c|}{ YOY§ and } & & & & \\
\hline & Larval & yearling & Adult & Larval & YOY§ & Yearling & Adult \\
\hline Zooplankton & $x$ & $\times$ & $x$ & $x$ & $\times \ddagger$ & & \\
\hline Benthos & & $x \dagger$ & $\times$ & $\times$ & $\times$ & $x$ & $x$ \\
\hline Forage fish & & & & & $\times$ & $\times$ & $x$ \\
\hline Larval perch & & & & $\times$ & $\times$ & $\times$ & \\
\hline Larval walleye & & & & $\times$ & $x$ & $\times$ & \\
\hline YOY perch & & & $\times$ & & $x$ & $\times$ & $x$ \\
\hline YOY walleye & & & & & $\times$ & $\times$ & $\times$ \\
\hline Yearling perch & & & & & & $\times$ & $\times$ \\
\hline Yearling walleye & & & & & & $\times$ & $\times$ \\
\hline
\end{tabular}

$\uparrow$ Yellow perch $>30 \mathrm{~mm}$.

\$ Walleye $<100 \mathrm{~mm}$.

$\S$ YOY are juvenile YOY, exclusive of larvae (i.e., YOY $>20 \mathrm{~mm}$ in length).

benthos to yellow perch is assumed to be zero for yellow perch $<30 \mathrm{~mm}$, and one for all yellow perch $\geq 30$ $\mathrm{mm}$. Of the fish prey types, only YOY juvenile yellow perch with length $<0.2$ of the predator length are assumed vulnerable to larger yellow perch (Post and Rudstam 1992). All other fish prey types are assumed unavailable (i.e., $V=0$ )

Vulnerabilities of prey types to walleye either depend on the biomasses of other prey types, are zero or one, or depend on the walleye length to prey length ratio. Vulnerability of zooplankton is one for walleye $<30 \mathrm{~mm}$ and zero for walleye $>100 \mathrm{~mm}$. Between these sizes, vulnerability depends on the biomasses of other prey types:

$$
V= \begin{cases}1.0 & \text { for } L<30 \mathrm{~mm} \\ \left(\frac{\mathrm{TB}_{\mathrm{z}}}{\mathrm{TB}_{\mathrm{z}}+\mathrm{TB}_{\mathrm{b}}+\mathrm{TB}_{\mathrm{f}}}\right)^{3} & \text { for } 30 \mathrm{~mm} \leq L \leq 100 \mathrm{~mm} \\ 0 & \text { for } L>100 \mathrm{~mm}\end{cases}
$$

where $\mathrm{TB}_{\mathrm{z}}$ is the biomass of zooplankton, $\mathrm{TB}_{\mathrm{b}}$ the biomass of benthos, and $\mathrm{TB}_{\mathrm{f}}$ is the biomass of forage fish, yellow perch, and walleye vulnerable to the predator, all expressed as $\mathrm{g} / \mathrm{m}^{3}$. The cubic function allows for 30-100 $\mathrm{mm}$ walleye to eat zooplankton when benthos and fish prey are low and to reduce zooplankton consumption when benthos and fish prey are abundant. A cubic function is used to model a greater than proportional (linear) reduction in zooplankton vulnerability when other prey types are available. Vulnerability of benthos to walleye is one for all walleye. Only fish prey whose length is $<0.6$ of the walleye length for walleye $<200 \mathrm{~mm}$, and $<0.4$ of the walleye length for walleye $>200 \mathrm{~mm}$, are vulnerable. These limits result in maximum prey lengths that can potentially be consumed similar to, or slightly longer than, observed maximum prey lengths in walleye diets (Forney 1978, Tarby and Forney 1978, Neilson 1980). There are no lower limits on the length of fish prey eaten by larval,
YOY juvenile, and yearling walleye; adult walleye only eat fish $>20 \mathrm{~mm}$ (Forney 1978, Knight et al. 1984, Campbell 1989, Knight and Vondracek 1993).

Mass per individual prey item is used to convert grams consumed to number consumed. Zooplankton and benthos use a fixed mass per individual. For forage and modeled fish prey types, the mean mass of each fish type is first used to convert grams eaten to numbers, and then that number of modeled individuals of each fish prey type are randomly selected. Lengths of forage fish individuals are generated from a normal distribution. Modeled fish prey individuals are evaluated in random order. For each fish prey individual eaten (i.e., vulnerable), consumption is increased by the mass of that individual fish prey. Because number consumed is based on the mean mass, and there is stochasticity in the masses of individuals randomly selected to be consumed, consumption can vary from that determined from the functional response relationship. Actual consumption is not allowed to exceed maximum consumption.

Predator half-saturation constants.-Half-saturation coefficients $\left(K_{i j}\right)$ are specified by size interval of yellow perch and walleye (see Table 4). Values of $K$ used in model simulations were determined by calibration. $K$ values for YOY and yearling yellow perch eating benthos are reduced by a factor of four between September and the following April, simulating yellow perch switching to benthos consumption over the winter.

\section{Feeding life stages: mortality}

Mortality rates of feeding larvae were determined by calibration. A larva dies if a generated uniform random number between 0 and 1 is less than the probability of dying, corresponding to its mortality rate. In addition, a larva can be killed if it is eaten by a YOY or yearling walleye (encounters are on an individual-by-individual basis).

Mortality of juvenile and yearling yellow perch and 
TABLE 4. Predator half-saturation coefficients $(K)$ used in the multispecies functional response relationship (Eq. 17) to model consumption by yellow perch and walleye. Units for $K$ values are no. individuals $/ \mathrm{L}$ for zooplankton, no. individuals $/ \mathrm{m}^{2}$ for benthos, and no. individuals $/ \mathrm{m}^{3}$ for fish prey types.

\begin{tabular}{|c|c|c|c|c|c|c|c|c|}
\hline \multicolumn{2}{|c|}{ Predator } & \multicolumn{7}{|c|}{ Prey } \\
\hline & & \multirow{2}{*}{$\begin{array}{l}\text { Zooplank- } \\
\text { ton }\end{array}$} & \multirow[b]{2}{*}{ Benthos } & \multirow{2}{*}{$\begin{array}{l}\text { Forage } \\
\text { fish }\end{array}$} & \multicolumn{2}{|c|}{ Yellow perch } & \multicolumn{2}{|c|}{ Walleye } \\
\hline Species & or age & & & & YOY & Yearling & YOY & Yearling \\
\hline Yellow perch & $\begin{array}{c}<20 \\
20-45 \\
45-100 \\
\geq 100 \\
\geq \text { age- } 2\end{array}$ & $\begin{array}{l}4.0 \\
2.0 \\
2.0 \\
5.0 \\
7.0\end{array}$ & $\begin{array}{r}6000 \\
300 \\
300 \\
400 \\
550\end{array}$ & & 4.5 & & & \\
\hline Walleye & $\begin{array}{c}<20 \\
20-45 \\
45-100 \\
100-200 \\
\geq 200 \\
\geq \text { age- } 2\end{array}$ & $\begin{array}{c}0.4 \\
0.65 \\
10.0 \\
150.0 \\
150.0\end{array}$ & $\begin{array}{r}220 \\
20 \\
60 \\
200 \\
400 \\
3000\end{array}$ & $\begin{array}{l}5.0 \\
0.5 \\
0.3 \\
0.1 \\
0.1 \\
0.3\end{array}$ & $\begin{array}{l}5.0 \\
1.6 \\
0.8 \\
0.5 \\
0.5 \\
0.2\end{array}$ & $\begin{array}{l}0.5 \\
0.5 \\
0.25\end{array}$ & $\begin{array}{l}5.0 \\
1.6 \\
0.8 \\
0.5 \\
0.5 \\
0.6\end{array}$ & $\begin{array}{l}0.5 \\
0.5 \\
0.6\end{array}$ \\
\hline
\end{tabular}

Note: Absence of a table entry indicates that the predator does not consume the prey type in question.

walleye is computed from consumption rates of modeled individuals. Predation by walleye and yellow perch typically accounts for nearly all the mortality of YOY juvenile and yearling stages in Oneida Lake (Forney $1977 b, c)$. A juvenile or yearling modeled fish is killed in the simulation if it is eaten by a YOY or yearling walleye (encounters are on an individual-byindividual basis). Daily probability of dying for a YOY juvenile or yearling from adult (walleye and yellow perch) predation is computed from the fraction of biomass consumed by adults. A random number between zero and one is generated, and, if it is less than the fraction consumed, then the individual is assumed eaten.

Mortality rates of adults ( $\geq$ age- 2 ) are treated as total (fishing plus natural) for yellow perch and divided into separate fishing and natural mortality components for walleye. Total annual instantaneous mortality rate of adult yellow perch is assumed equal to $0.5 \mathrm{yr}^{-1}$ (Lloyd 1996). Annual instantaneous natural mortality for $\geq$ age- 2 walleye is assumed equal to $0.06 \mathrm{yr}^{-1}$ (Gros- slein 1961, Forney 1967). We assumed that fishing applies to all $\geq$ age- 3 walleyes, because mean lengths of age- 3 are similar to the 12 inch $(305 \mathrm{~mm})$ size limit imposed during much of the period of record, while mean lengths of age- 2 are consistently $<305 \mathrm{~mm}$. Fishing mortality rate is month-specific and inversely related to the biomass of available forage (Fig. 1, Lloyd 1996). In model simulations, annual walleye harvest rates of $55-65 \%$ are typical. Annual walleye yield is computed in biomass (kg/ha) and numbers (no. individuals/ha).

\section{Numerical considerations}

All modeled individuals represent some number of identical individuals in the population. In this paper, all simulations followed 200 modeled YOY and 200 yearling individuals. The 200 YOY individuals are selected from spawners each year, while maintaining the correct relative proportions of first feeders coming from each female. On 10 April of each year, 50 modeled age-2 individuals are randomly selected from the 200

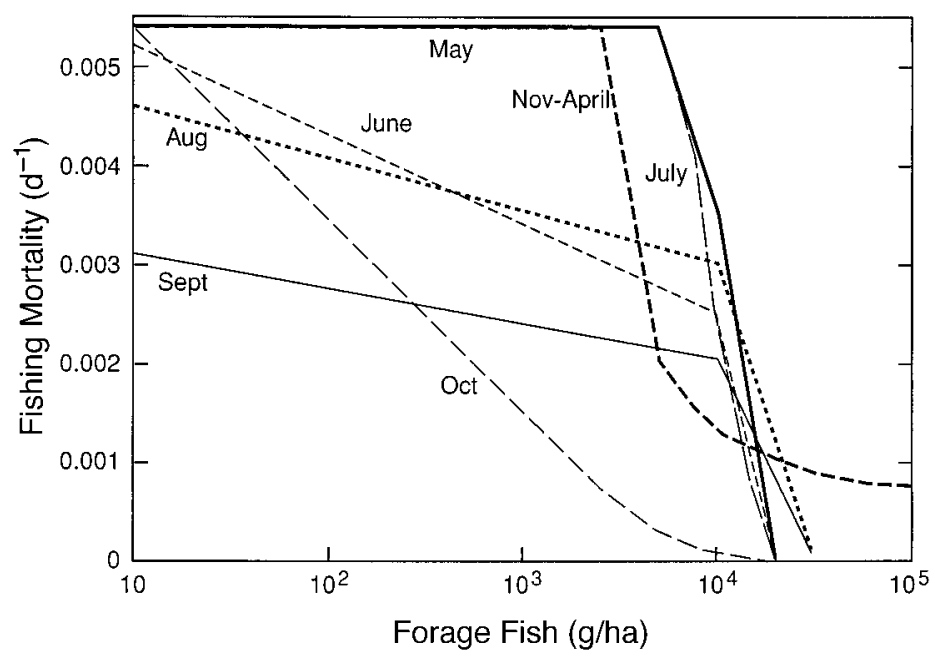

FIG. 1. Month-specific relationships between fishing mortality rate of adult walleye $\left(\mathrm{d}^{-1}\right)$ and total biomass of forage fish (from Lloyd 1996). Mortality shown is assumed to occur at the middle of each month; values for other days are linearly interpolated between adjoining months. Forage fish is computed daily in the model as the biomass $(\mathrm{g} / \mathrm{ha})$ of forage fish and YOY and yearling yellow perch and walleye. No fishing mortality is applied during March and April, when the fishing season is closed. 
surviving yearling individuals, and these are followed through their lifetime. A constant number of modeled individuals per age class are maintained in the model by using resampling for YOY and yearling (Rose et al. 1993) and by decrementing the number of population individuals represented by each modeled adult individual (Scheffer et al. 1995).

Predator-prey encounters and mortality rates based on modeled individuals are scaled up to population individuals and updated after each YOY predator or yearling predator is evaluated. Individual YOY and yearling predators encounter other individual YOY and yearling as prey. Daily computation of the ratio of total predator consumption to total prey biomass, by prey length categories, approximates the daily probability of juveniles and yearlings being eaten by adults. This is done to avoid the computational expense of nested loops of every adult individual evaluating every YOY and yearling individual. We update the status of the YOY and yearling yellow perch and walleye individuals after each YOY and yearling predator is evaluated. This prevents a modeled prey fish individual from being eaten several times in a day by different fish predator individuals, and prevents total consumption on a day from exceeding the number of prey present. Modeled YOY and yearling yellow perch and walleye are evaluated for growth and mortality in random order each day to avoid giving those individuals evaluated early in the day the advantage of experiencing more prey.

\section{Design of Model Simulations}

\section{Baseline, mayflies, forage fish, stocking, and prediction variables}

Model simulations used combinations of baseline, increased mayfly, increased forage fish, and walleye stocking conditions. Baseline conditions correspond to the model as described above. Increased mayflies was simulated by using $2 \times, 3 \times, 4 \times$, or $5 \times$ the equilibrium benthos densities, and by eliminating adult yellow perch and walleye consumption of fish prey and walleye fishing mortality from 5 June-19 July of every year. Although summertime mayfly biovolumes during 1956-1959 were similar to chironomid biovolumes during the baseline period (Jacobsen 1966, Clady and Hutchinson 1976), the larger size of mayflies and their greater availability likely resulted in increased consumption of benthos by fish. Yellow perch showed strong selection for mayflies, with the frequency of occurrence of mayflies in perch diets declining only $\sim 3$-fold, despite a 10-fold decline in mayfly biomass (Clady and Hutchinson 1976). The density of mayflies available to walleye and yellow perch adults is not known, as mayflies clearly satiated fish predators during their emergence. The range of $2 \times-5 \times$ benthos densities likely encompasses the increase in benthos prey observed in Oneida Lake during the mayfly period. We eliminate fishing mortality on walleye and do not allow consumption of forage fish, yellow perch, and walleye during the mayfly period to simulate that observed adult fish diets in Oneida Lake consisted of almost all mayflies during the peak emergence. Multiplying the equilibrium densities of the forage fish prey group by $3 \times, 5 \times$, or $7 \times$ simulates increased forage fish. Average juvenile white perch abundance during 1979-1985 was 5.4-fold higher than during the baseline period (Cacela 1989).

Walleye yolk sac larvae have been stocked annually in Oneida Lake. We simulate stocking in the model by adding 10200 first-feeding walleye $(9.0 \mathrm{~mm}, 0.0042$ g) on 10 May of every year. Actual numbers stocked have varied from 0-15000 larvae/ha (average of 6750 larvae/ha) during 1966-1976; since 1980, 5000 larvae/ ha have been added between 28 April and 15 May. Adding 5000 yolk sac larvae/ha corresponds to adding 33800 yolk sac larvae to the 6.76-ha model box. We reduce this number to 10200 first feeding larvae, assuming $30 \%$ survival from hatch to first feeding. Walleye first feeders are added on 10 May, corresponding to about $8 \mathrm{~d}$ (average yolk sac stage duration) after the average date walleye are stocked in Oneida Lake.

All simulations started with typical size and age distributions of spawning adults. The first $15 \mathrm{yr}$ of each simulation were ignored to eliminate initial condition effects and allow populations to establish themselves; average values and coefficients of variation (CVs) were computed based on all subsequent years. Recruitment is defined as the abundance of yearlings in October. For both corroboration and hypothesis evaluation simulations, we report predicted abundances, mean lengths, and survival rates for life stages and months consistent with Oneida Lake data. Predicted adult abundances refer to total abundances of fish >age-3 for yellow perch and $>$ age- 4 for walleye to be consistent with abundances reported from Oneida Lake. We use lengths, growth rates, and percent mature of selected ages to illustrate adult dynamics (age-4 for yellow perch; age-5-6 for young walleye; and age-9-10 for old walleye). Yellow perch and walleye adult survival rates are not compared among simulations, because their values in hypothesis evaluation simulations were similar to baseline values.

\section{Calibration and corroboration}

Model calibration was achieved by adjusting selected model parameters until model predictions under baseline conditions were qualitatively similar to observed values for the baseline period. The only parameters adjusted during calibration were the following: values of predator half-saturation coefficients $\left(K_{i j}\right)$, larval mortality rates, and the value of the YOY yellow perch refuge level. All other parameters were maintained at their initially assigned values. We used predicted YOY, yearling, and adult yellow perch and walleye abundances and mean lengths at age as criteria to 
determine when model output was similar to baseline period values. Results of the calibration simulations are not presented separately, because similar results are included as part of the model corroboration. Trial and error variation of parameter values was used. Thus, the final set of calibrated parameter values is not necessarily the best nor is it unique. Other combinations of parameter values may exist that could generate even better model fits to the data. The complexity of the model and calibration prevented easy use of objective calibration methods.

Model corroboration was achieved by comparison of model predictions to observed data from simulations that mimicked the historical time sequence of high mayfly, baseline, and high forage fish periods in Oneida Lake. Baseline conditions were simulated for years 115 to eliminate initial condition effects. Walleye stocking was imposed annually, beginning in year 16. Increased mayfly densities were then imposed from years 26-35, baseline conditions for years 36-45, and increased forage fish densities from years 46-55. Two corroboration simulations were performed that used $3 \times$ and $5 \times$ mayfly and forage fish densities.

Predicted diets were qualitatively evaluated for their realism, and two sets of model predictions were graphically compared to observed Oneida Lake data. The percent of biomass consumed during September of each prey type by YOY, yearling, and adults was used to check predicted diets. Maximum population consumption rates of prey occur in the late summer and early fall for both species. We compared observed and predicted magnitudes of abundances, survival rates, and mean lengths at age. We also compared nine predicted and observed relationships (patterns) among YOY growth rates, mortality rates, and abundances. For both sets of comparisons, observed values from the entire period of record were used.

Only the comparison of the nine YOY relationships is truly model corroboration. The model was not calibrated to generate these relationships, and model performance was evaluated only after calibration was completed. Comparisons of predicted and observed diets, and abundances and mean lengths at age (as part of the first set of comparisons) are not truly model corroboration. The model was fit to the same variables for the baseline period as part of model calibration. The diet, abundances, and mean lengths at age under the corroboration simulations serve as a check that model behavior under altered forage fish and mayflies is still realistic. We purposely allow for different $x$ - and $y$ scales when comparing predictions and observations for each of the nine YOY relationships. Our emphasis is on whether the model predicts the same patterns in the relationships as those that are observed. Ensuring that the model predicts realistic magnitudes of abundances and mean lengths was established as part of calibration and the first set of corroboration comparisons.
Statistical analyses of the nine relationships among YOY growth rates, mortality rates, and abundances showed little differences among periods, thereby supporting combining data from all three periods together. We fit a suite of linear regression models relating the response variable to the explanatory variable (various combinations of linear, quadratic, and $\log _{e}$-transformed explanatory variable) for each of the nine relationships. We then refit the best of the models (highest $R^{2}$ ), with slopes specific to each period. Period-specific slopes were not significantly different across periods $(P>$ 0.05 ) for seven of the nine relationships. One-way ANOVA (with period as the treatment) applied to each explanatory variable and to each response variable showed that average values of six of the nine response variables, and six of the eight unique explanatory variables, were not significantly different among periods. Differences in other variables (e.g., actual stocking levels or fishery regulations) among periods further complicate period-specific comparisons.

\section{Hypothesis evaluation}

Simulations to evaluate the three hypotheses were performed without walleye stocking to emphasize the biological interactions between yellow perch and walleye. Stocking acts to partially uncouple yellow perch and walleye interactions by annually adding a constant number of walleye, independent of all other conditions. We compared baseline simulations with and without walleye stocking to show that walleye stocking had little effect on adult abundances.

We performed 50-yr simulations of baseline, increased mayflies alone, and increased forage fish densities alone to isolate the effects on yellow perch and walleye dynamics of alternative prey for walleye. A range of increasing densities of benthos $(2 \times, 3 \times, 4 \times$, $5 \times)$ and forage fish $(3 \times, 5 \times, 7 \times)$ were imposed to confirm any patterns in responses. To test whether alternative prey stabilized the walleye and yellow perch populations (hypothesis 1), CVs of annual YOY in October, recruitment, and adult abundances were compared among the baseline, mayflies, and forage fish simulations. Average predicted recruitments were compared among simulations to evaluate the hypothesis that alternative prey causes higher recruitment (hypothesis 2). Average predicted values of abundances, recruitment, mean lengths, growth rates, survival rates, fecundity, percent mature at age, and walleye cannibalism rates were used to explain model responses.

Compensation (hypothesis 3) was evaluated by analyzing the response of yellow perch and walleye to changes in their egg mortality rates under baseline conditions. Four simulations were performed corresponding to increased and decreased egg mortality rate of each species. Many anthropogenic stresses involve increased mortality of YOY life stages. We opted to vary egg mortality, because egg stage survival is densityindependent, enabling easy control of how many in- 
dividuals are removed. The baseline yellow perch egg mortality rate of $0.11 \mathrm{~d}^{-1}(10 \%$ survival rate) was increased to $0.15 \mathrm{~d}^{-1}$ (4\% survival) and decreased to 0.06 $\mathrm{d}^{-1}$ (29\% survival). The baseline walleye egg mortality rate of $0.14 \mathrm{~d}^{-1}$ ( $6 \%$ survival) was increased to 0.18 $\mathrm{d}^{-1}\left(2.5 \%\right.$ survival) and decreased to $0.075 \mathrm{~d}^{-1}(22 \%$ survival). These changes were selected because they significantly affected model dynamics while still resulting in realistic adult abundances and mean lengths at age. Predicted average values of abundances, mean lengths, growth rates, survival rates, fecundity, and percent mature at age were analyzed for density-dependent responses. Results are described in terms of increasing egg mortality (i.e., from decreased egg mortality to baseline to increased egg mortality), rather than relative to baseline results, as is done for hypotheses 1 and 2 .

\section{Simulation Results}

\section{Calibration and corroboration}

Calibrated parameter values resulted in realistic abundances and lengths at age. Predicted and observed values are compared as part of the model corroboration. Calibrated $K$ values are listed in Table 4. Calibrated larval mortality rates were significantly higher for walleye $\left(0.2 \mathrm{~d}^{-1}\right)$ than for yellow perch $\left(0.03 \mathrm{~d}^{-1}\right)$. Estimated larval mortality rates of walleye in Oneida Lake $\left(\sim 0.2 \mathrm{~d}^{-1}\right.$, Noble 1972) were higher than or similar to those estimated for yellow perch $\left(0.04-0.12 \mathrm{~d}^{-1}\right.$, Tarby and Forney 1978; $0.2 \mathrm{~d}^{-1}$, Noble 1968). The YOY yellow perch refuge was set to $411 \mathrm{~g} / \mathrm{ha}$, or $\sim 5 \%$ of the average predicted YOY yellow perch biomass in October.

Model predictions of yellow perch and walleye dynamics under the $3 \times$ and $5 \times$ corroboration simulations were consistent with dynamics observed in Oneida Lake. Predicted yellow perch and walleye adult abundances exhibited predator-prey cycles that were made noisy by the mayfly, baseline, and forage fish effects (Fig. 2). Model predicted abundances are not expected to track observed abundances on a year-by-year basis. Model simulations are based only on varying benthos and forage fish densities, and they do not include the historical variation in other factors (e.g., temperature or fishing) that affected actual yellow perch and walleye abundances in Oneida Lake.

Mean abundances, survival rates, and lengths at age of yellow perch and walleye were similar to observed values (Fig. 3). This was expected because the model was calibrated to values observed for the baseline period. The major differences between predictions and observed data were as follows: (1) higher predicted over-winter (October-May) survival rates of yellow perch (Fig. 3b), (2) higher predicted August-October YOY walleye survival rates (Fig. 3e), and (3) greater variation in mean lengths of adult walleye (Fig. 3f). Our goal was to obtain order-of-magnitude agreement between predicted and observed abundances. Differences between predicted and observed egg-to-recruit-

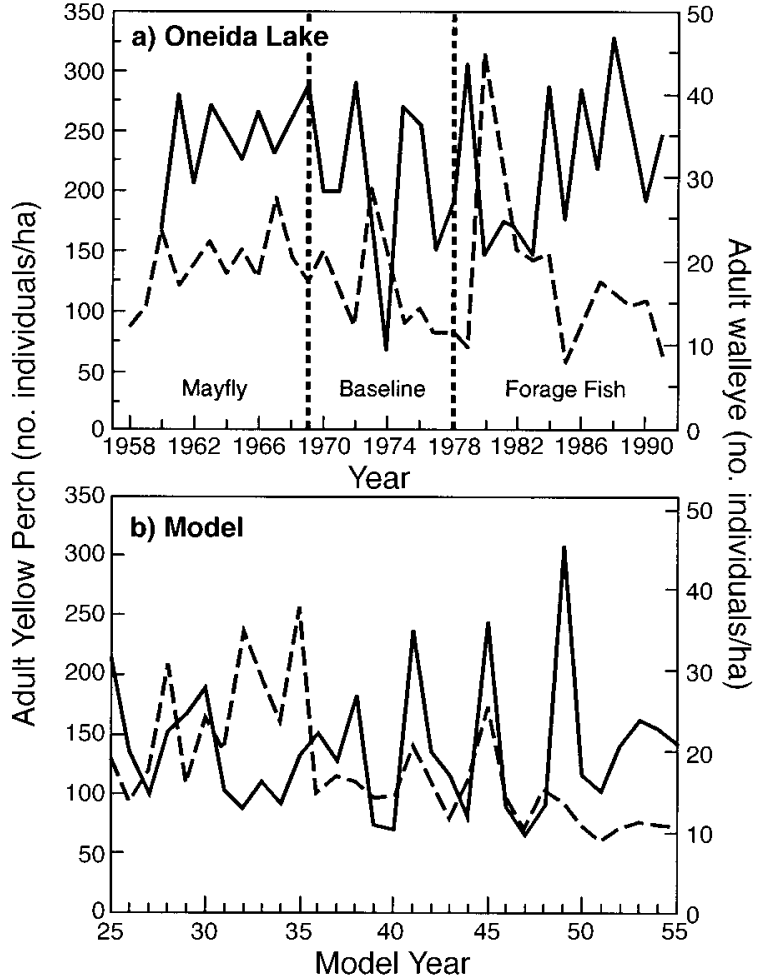

FIG. 2. Annual abundances (no. individuals/ha) of adult yellow perch and walleye in May for (a) 1958-1991 in Oneida Lake and (b) $5 \times$ model corroboration simulation. Yellow perch abundance, --- ; walleye abundance, - . Dashed vertical lines separate the mayfly, baseline, and forage fish periods.

ment survival rates of yellow perch and walleye led to $\sim 2$-fold higher predicted recruitment (not apparent in Fig. 3a, d). Simulated diets of yellow perch consisted of a mix of zooplankton and benthos in September (Fig. 4). Walleye diets included benthos, forage fish, yellow perch, and walleye, with fish increasing in importance and benthos decreasing in importance from YOY to yearling to adult stages (Fig. 4). Quantitative comparison of predicted and observed diets is not possible, because observed diets were recorded as the frequency of stomachs containing each prey type. Predicted diets are generally reasonable, except that yearling walleye consumed too much benthos $(56 \%)$ relative to fish (44\%). Forney (1974) reported that fish prey dominated the diets of yearling walleye (200-240 mm). Predicted average walleye yield was $8.5 \mathrm{~kg} / \mathrm{ha}$ (range of 2-18 $\mathrm{kg} / \mathrm{ha}$ ) and 14.6 individuals/ha (5-34 individuals/ha). Lloyd (1996), using a model based on statistical relationships linking survival between life stages, estimated typical walleye fishery yields in Oneida Lake to be $3-10 \mathrm{~kg} / \mathrm{ha}$ and $2-10$ individuals/ha.

With one exception, model-generated and observed relationships among YOY growth rates, mortality rates, and abundances exhibited similar patterns. Walleye and yellow perch October mean lengths were negatively 

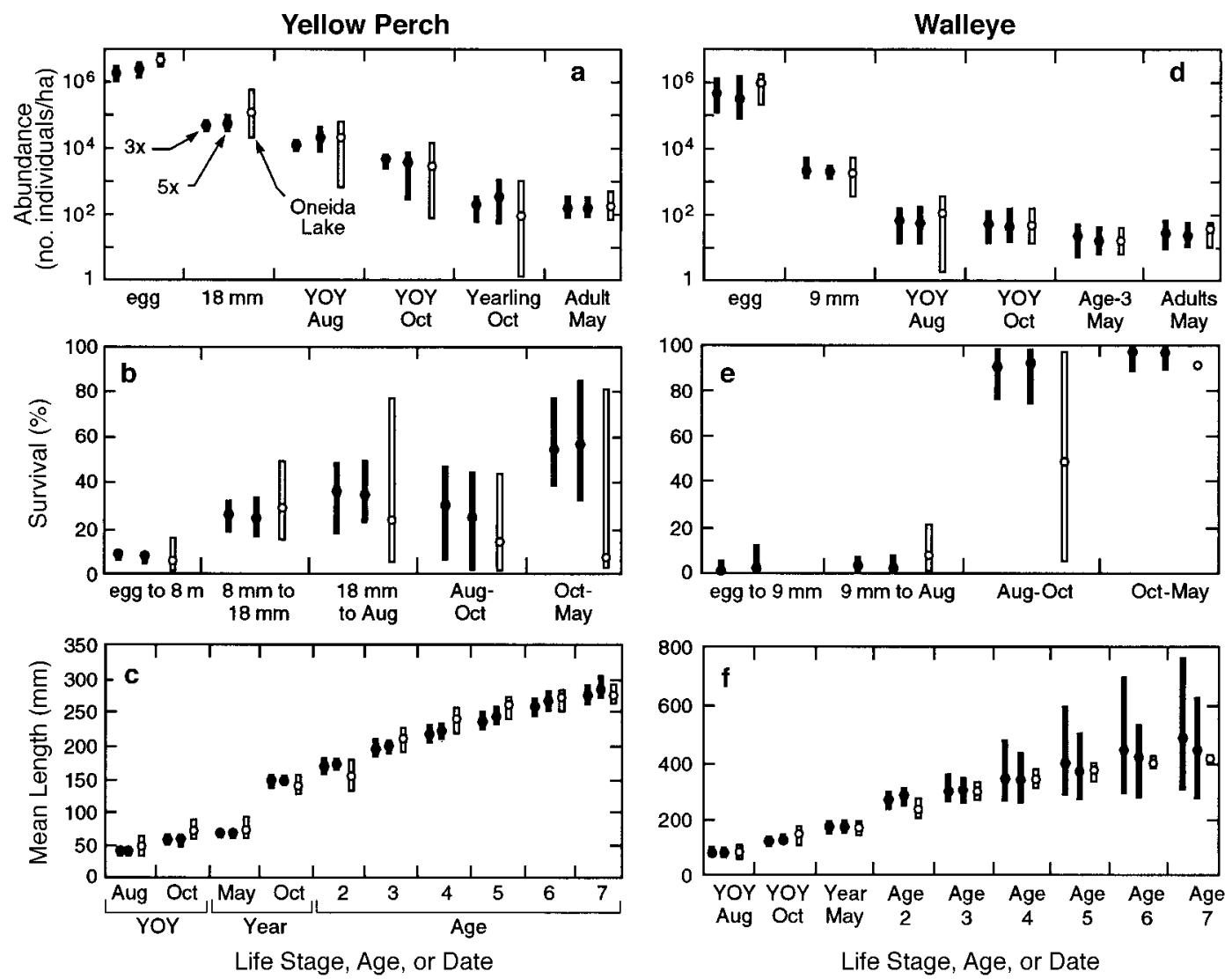

FIG. 3. Predicted and observed minimum, mean, and maximum values for yellow perch (a) abundances, (b) survival rates, and (c) mean lengths; and for walleye (d) abundances, (e) survival rates, and (f) mean lengths. Predicted values are for years 25-55 of the 55-yr corroboration simulations, with walleye stocking and increased mayfly densities in years $25-$ 35 , baseline conditions in years 35-45, and increased forage fish densities in years 45-55. Mayfly and forage fish densities were increased by multiplying their equilibrium densities by 3 or 5 ( $3 \times$ and $5 \times$, respectively). Observed values are for Oneida Lake for 1958-1990. Observed mean lengths are shown for ages 1-6; estimation of $\geq$ age-7 walleye is unreliable. Oneida Lake data are shown as the rightmost (open) bar. The $5 \times$ mayflies and forage fish simulation is shown as the center (solid) bar. The $3 \times$ mayflies and forage fish simulation is shown as the leftmost (solid) bar.

related to abundances and to the ratio of yellow perch to walleye lengths (Fig. 5). YOY mortality rates were negatively related to YOY mean lengths and to available walleye forage for yellow perch (Fig. 6) and for walleye (Fig. 7). The exception was a positive relationship in model output between the yellow perch October-May (over the winter) mortality rate and October mean length, which was a negative relationship in the data (Fig. 6b). In model simulations, the depensatory relationship between mortality rate during August-October and the number of YOY yellow perch per walleye (Fig. 6c) continued into the winter period. Longer mean YOY yellow perch in October were associated with lower yellow perch abundances (Fig. 5c), which, in turn, were associated with decreased yellow perch per walleye and a higher mortality rate.

\section{Effects of walleye stocking}

Model predictions under baseline conditions were similar in magnitude and periodicity with and without walleye stocking (Fig. 8). Predicted adult abundances did not match on a year by year basis. Walleye stocking resulted in a 2.3-fold increase in $9 \mathrm{~mm}$ abundance (from $685 /$ ha to $1559 /$ ha), similar to the $\sim 3$-fold increase observed in Oneida Lake. Walleye stocking had little effect on yellow perch dynamics, while adult walleye abundances increased slightly (from 19.9 individuals/ ha to 21.1 individuals/ha) and exhibited less interannual variation (CV from 57 to $47 \%$ ).

\section{Effects of alternative prey on stability (hypothesis 1) and recruitment (hypothesis 2 )}

Increased mayflies and forage fish reduced interannual variation in walleye abundances, but produced mixed results for yellow perch abundances (Fig. 9). Coefficients of variation of YOY walleye abundances in October, recruitment, and adult abundances were generally smaller for increased mayflies and forage fish densities than for baseline conditions. Under the highest increase in mayflies $(5 \times)$, CVs began to increase again, although they remained below baseline levels. For small increases in mayfly densities $(2 \times$ and $3 \times)$, 
CVs of YOY yellow perch abundance in October and of recruitment were also below baseline levels. However, CVs of YOY yellow perch abundance in October and of recruitment increased with increasing mayfly densities, exceeding baseline values with the $5 \times$ increase in mayfly density. While CVs of YOY yellow perch abundances in October declined slightly with increasing forage fish densities, CVs of recruitment were similar to or exceeded the baseline $\mathrm{CV}$ value. CVs of yellow perch adult abundances under all levels of mayfly and forage fish densities were similar to baseline values.

Increased mayfly densities resulted in higher yellow perch recruitment for all levels of increase (Table 5). Mayflies buffered YOY yellow perch from walleye predation, resulting in an increased survival of yellow perch from $18 \mathrm{~mm}$ to August. Higher YOY yellow perch abundances in August resulted in shorter mean lengths in October due to reduced zooplankton densities. Increased mayfly densities led to longer walleye recruits (Table 6). Shorter YOY yellow perch and longer yearling walleye combined to cause higher walleye predation on YOY yellow perch and a decreased August-October survival rate of YOY yellow perch. A lower abundance of YOY yellow perch in October resulted in shorter walleye adult mean lengths (Table 6), less predation pressure on yearling yellow perch due to lower walleye consumption rates, and thus an increased YOY yellow perch October to recruitment survival rate (Table 5). The increased survival rate of YOY yellow perch from October to recruitment more than offset the decreased survival rate of YOY during August-October. Thus, yellow perch recruitment increased with increasing mayfly densities. Higher recruitment led to higher adult abundances, which achieved near baseline mean lengths, because increased mayfly densities increased adult yellow perch growth, offsetting the shorter YOY October lengths. Maturation and fecundity were similar to baseline values; higher adult abundances led to more spawners and increased egg production and $18 \mathrm{~mm}$ abundances.

Small increases in mayfly densities $(2 \times$ and $3 \times)$ caused higher walleye recruitment, whereas large increases in mayfly densities $(4 \times$ and $5 \times$ ) lowered walleye recruitment (Table 6). Mean lengths of walleye recruits increased with increasing mayfly densities. Adult growth rates decreased under increasing mayfly densities. Longer YOY and yearling walleye consumed more YOY yellow perch (October yellow perch abundances declined with increasing mayfly densities, Table 5) leaving less food for adult walleye. Slower adult walleye growth led to shorter adults, older age of maturation, fewer spawners, decreased egg production, and lowered $9 \mathrm{~mm}$ abundances. Increased mayfly densities reduced cannibalism, causing an increase in survival from $9 \mathrm{~mm}$ to recruitment. Recruitment increased for $2 \times$ and $3 \times$ mayfly densities, due to reduced cannibalism more than offsetting lowered egg production.

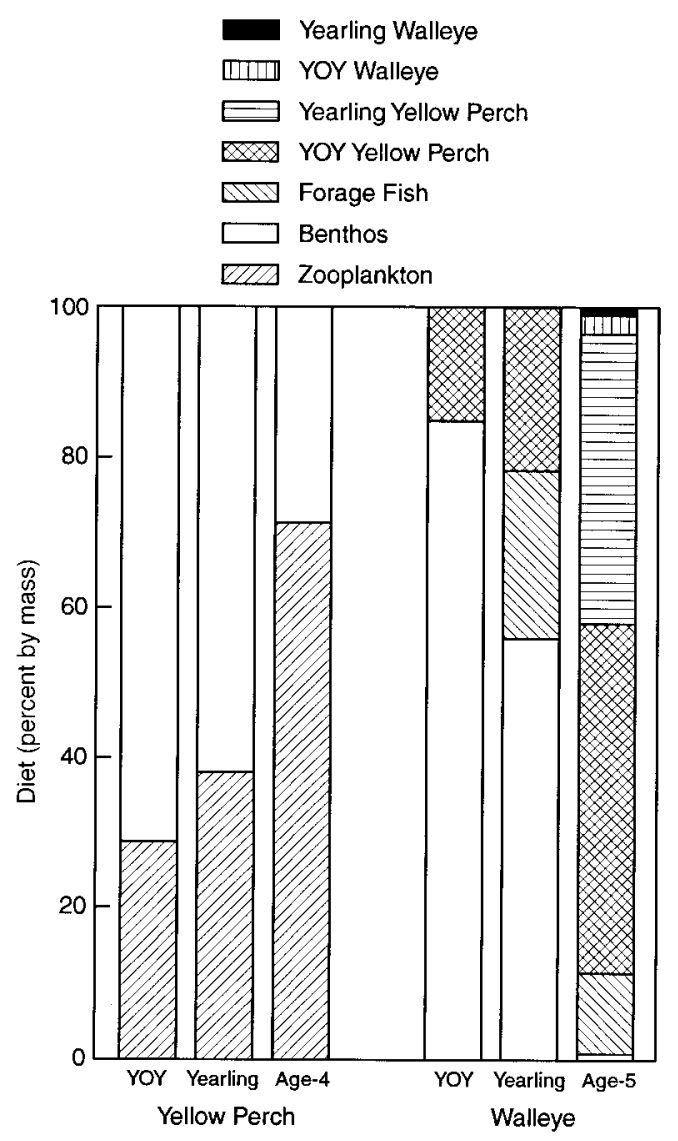

FIG. 4. Predicted September diets of YOY juvenile, yearling, and adult yellow perch and walleye for the $5 \times$ corroboration simulation. Adult diets are represented by age- 4 for yellow perch and by age-5 for walleye.

Recruitment was similar to baseline values for $4 \times$ and $5 \times$. Adult abundances and yield, in no. individuals/ha, mimicked the trends in recruitment levels. Yield in kilograms per hectare was slightly higher than baseline at $2 \times$ and $3 \times$ mayfly densities (due to higher adult abundances and similar to baseline mean lengths), but lower than baseline for $4 \times$ and $5 \times$ mayfly densities (due to smaller adults).

Increased forage fish densities lowered yellow perch recruitment (Table 7). Increased forage fish resulted in longer yearling and adult walleye (Table 8), which decreased survival of yellow perch from $18 \mathrm{~mm}$ to recruitment, and lowered YOY yellow perch August and October abundances and recruitment. Lowered YOY and yearling perch abundances led to longer recruit mean lengths, and, with near baseline adult growth rates, longer adults that matured at younger ages. Younger maturation and higher fecundity offset lowered adult abundances that resulted from lowered recruitment, and egg production and $18 \mathrm{~mm}$ abundances were similar to baseline values.

Walleye recruitment was slightly higher with increased forage fish densities (Table 8). Mean lengths 
a)

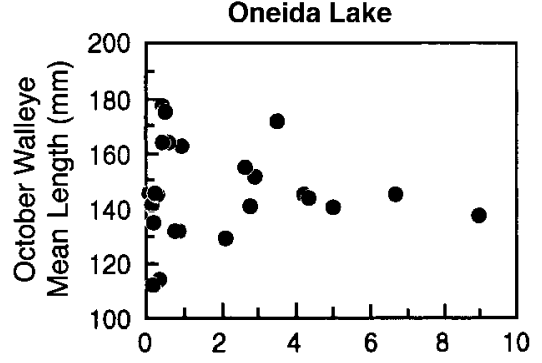

$5 \times$ Model

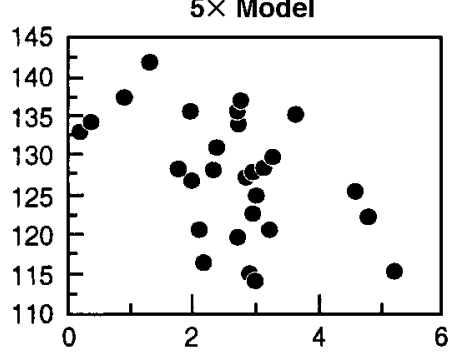

$3 \times$ Model

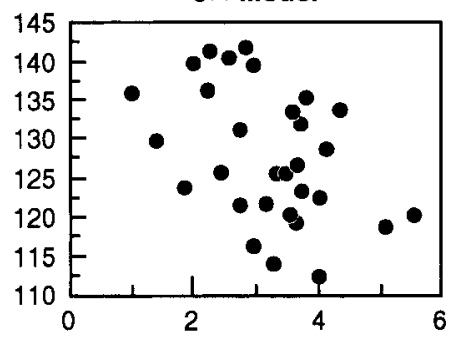

October Yellow Perch (no. individuals/ha $\times 10^{-3}$ )

b)

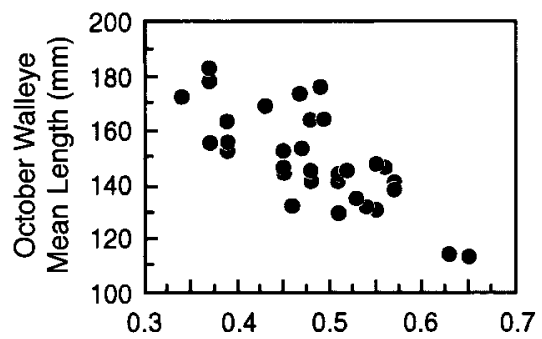

c)

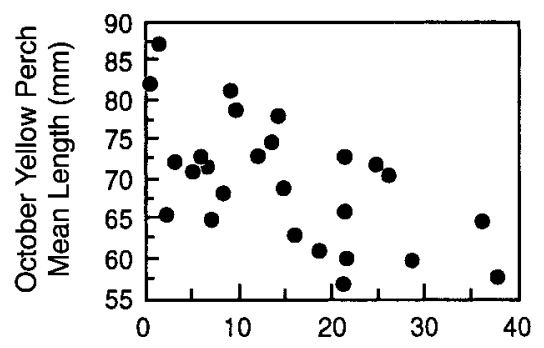

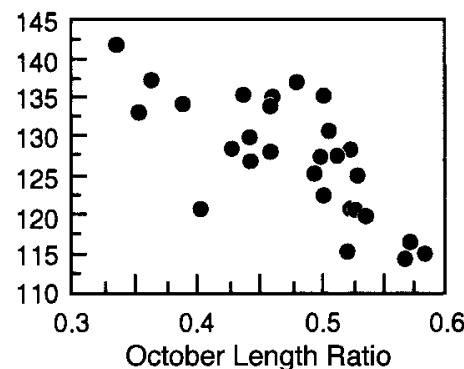
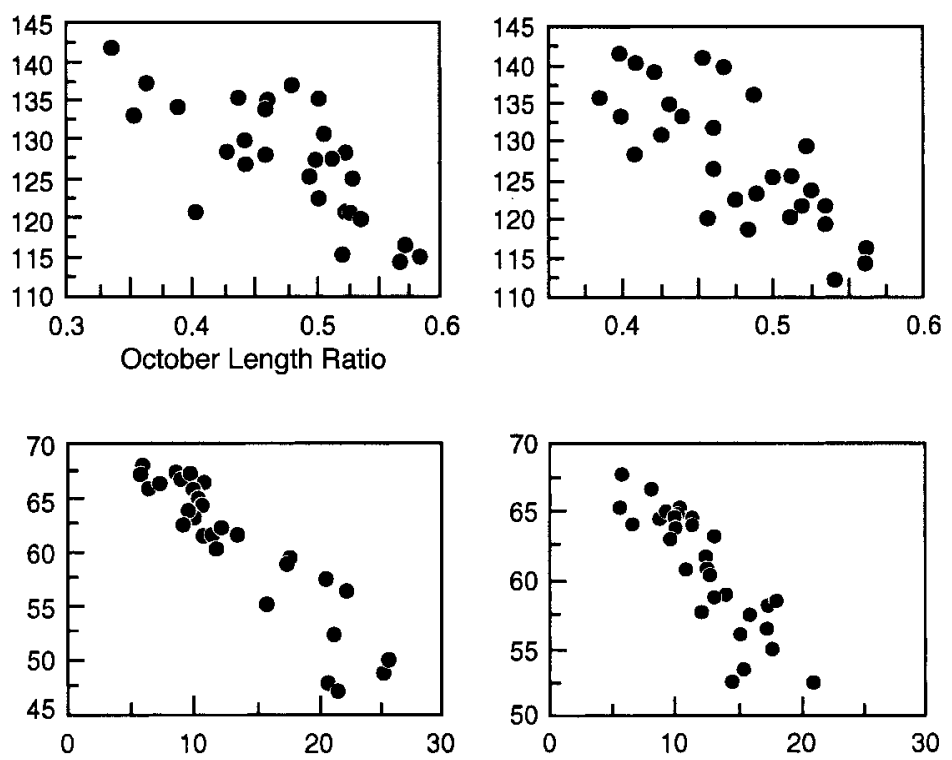

August Yellow Perch (no. individuals/ha $\times 10^{-3}$ )

FIG. 5. Predicted and observed YOY relationships involving mean lengths and abundances. Predicted relationships are from years $25-55$ of the $3 \times$ and $5 \times$ corroboration simulations. Note that predicted and observed values are not plotted on the same $x$ - and $y$-scales, since we wish to emphasize the comparison of patterns rather than magnitudes. (a) Walleye mean length in October vs. yellow perch abundance in October, (b) walleye mean length in October vs. the ratio of mean October yellow perch length to mean October walleye length, and (c) yellow perch mean length in October vs. yellow perch August abundance.

of walleye recruits increased with increasing forage fish densities, resulting in reduced cannibalism (slightly higher YOY August to recruitment survival) and higher recruitment, adult abundances, and yield in number of individuals per hectare. Higher adult abundances resulted in slower adult growth rates; nevertheless, longer recruits more than offset slower adult growth rates, and young adults were longer and matured earlier, resulting in more spawners. However, longer recruits and young adults consumed yellow perch prey normally available to older walleye under baseline conditions. Older walleye adults were shorter than baseline values, resulting in lowered fecundity. More spawners and lowered fecundity resulted in egg production, $9 \mathrm{~mm}$ abundances, and abundances of YOY in October similar to baseline values. The complex changes in adult mean lengths offset lower yield in number of individuals per hectare, with the result that yield in kilograms per hectare was similar to baseline values.

\section{Compensation (hypothesis 3)}

Yellow perch exhibited density-dependent responses to increasing yellow perch egg mortality (Table 9). Increasing egg mortality led to the expected lower total number of first feeders and $18 \mathrm{~mm}$ abundance. The survival rate of yellow perch from $18 \mathrm{~mm}$ to recruitment increased with increasing egg mortality, resulting in slightly increased recruitment. Yellow perch survival increased due to decreased walleye predation pressure; adult walleye abundances decreased with increasing yellow perch egg mortality (from 20.2 individuals/ha to 19.9 individuals/ha to 16.1 individuals/ha). Yellow perch growth rates increased (longer mean recruit and adult lengths) with increasing egg mortality. Longer 
a)

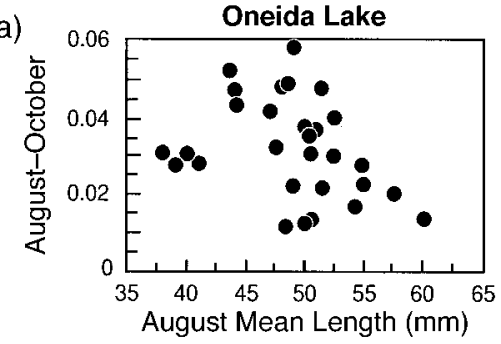

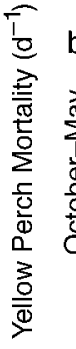

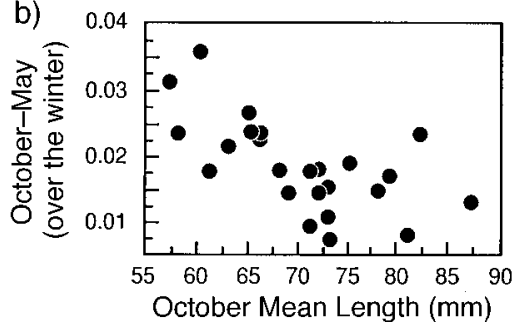

c)

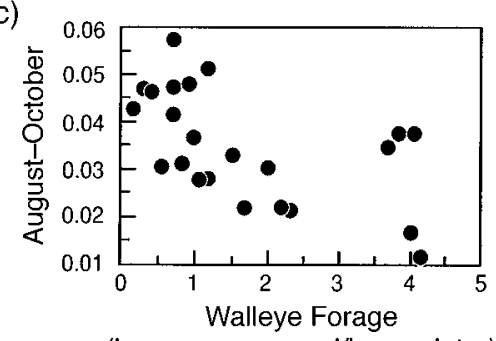

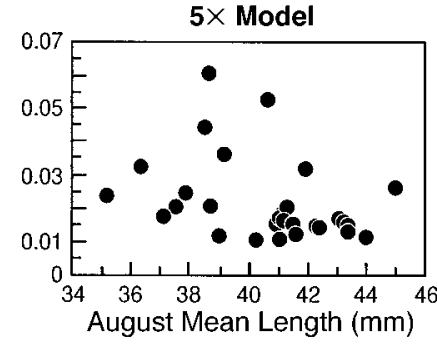
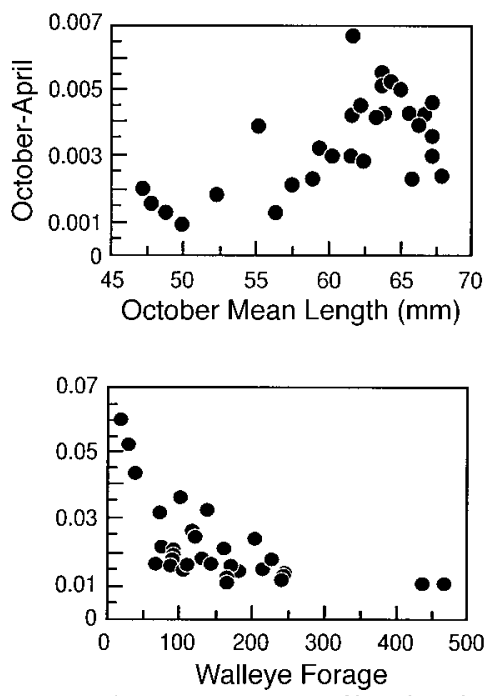

(no. prey consumed/predator)
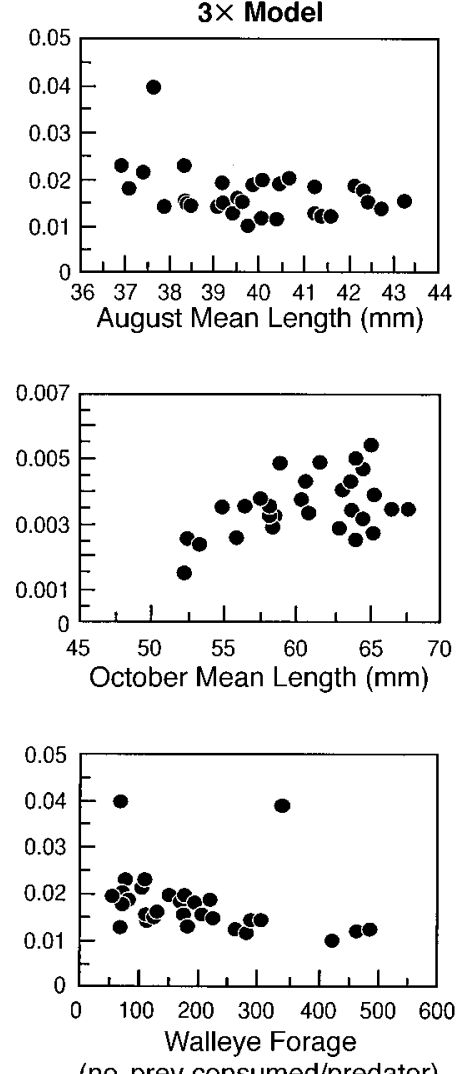

(no. prey consumed/predator)

FIG. 6. Predicted and observed YOY relationships between yellow perch mortality rates and mean lengths and walleye forage. Predicted relationships are from years $25-55$ of the $3 \times$ and $5 \times$ corroboration simulations. Note that predicted and observed values are not plotted on the same $x$ - and $y$-scales, since we wish to emphasize the comparison of patterns rather than magnitudes. (a) Yellow perch mean August-October mortality rate vs. yellow perch mean length in August, (b) yellow perch mean mortality rate during October-May of the next year vs. yellow perch mean length in October, and (c) yellow perch mean August-October mortality rate vs. forage (forage fish and YOY and yearling yellow perch and walleye) available to walleye. Note that walleye forage is expressed differently between Oneida Lake and model values.

adults resulted in a younger age of maturation and slightly higher fecundity. With adult abundances near or slightly above baseline levels, younger age of maturation resulted in more spawners with increasing egg mortality. More spawners and higher fecundity resulted in increased egg production to compensate for increased egg mortality.

Walleye also exhibited density-dependent responses with increasing walleye egg mortality rates (Table 10). Increasing egg mortality resulted in the expected lowered total number of first feeders and $9 \mathrm{~mm}$ abundances. Walleye $9 \mathrm{~mm}$ to August survival increased with increasing egg mortality, but not enough to offset the increased egg mortality, and recruitment and adult abundances declined. While mean lengths of recruits were similar among simulations, adult growth rate increased with increasing egg mortality. Adult lengths increased with increasing egg mortality (clearer for age-6 than for age-5). Yield in no. individuals/ha mimicked adult abundances and decreased with increasing egg mortality. Yield in kilograms per hectare increased slightly with increasing egg mortality due to larger walleye offsetting the decline in the number of individuals harvested per hectare. Longer walleye with increasing egg mortality resulted in younger maturation, more adults being spawners, and increasing spawner abundances. More spawners (and increased mean fecundity for increased mortality) more than offset lowered adult abundances, resulting in increasing egg production with increasing egg walleye mortality rate.

\section{Discussion}

Oneida Lake data were suggestive of three hypotheses concerning yellow perch and walleye dynamics. The hypotheses were as follows: (1) alternative walleye prey stabilize the yellow perch and walleye populations, (2) alternative prey increases yellow perch and walleye recruitment, and (3) yellow perch and walleye exhibit density-dependent growth and survival in response to changed YOY survival rates. We now discuss our modeling results by investigating these hypotheses under the headings of predator-prey dynamics, density dependence, model weaknesses, and knowledge gaps. 

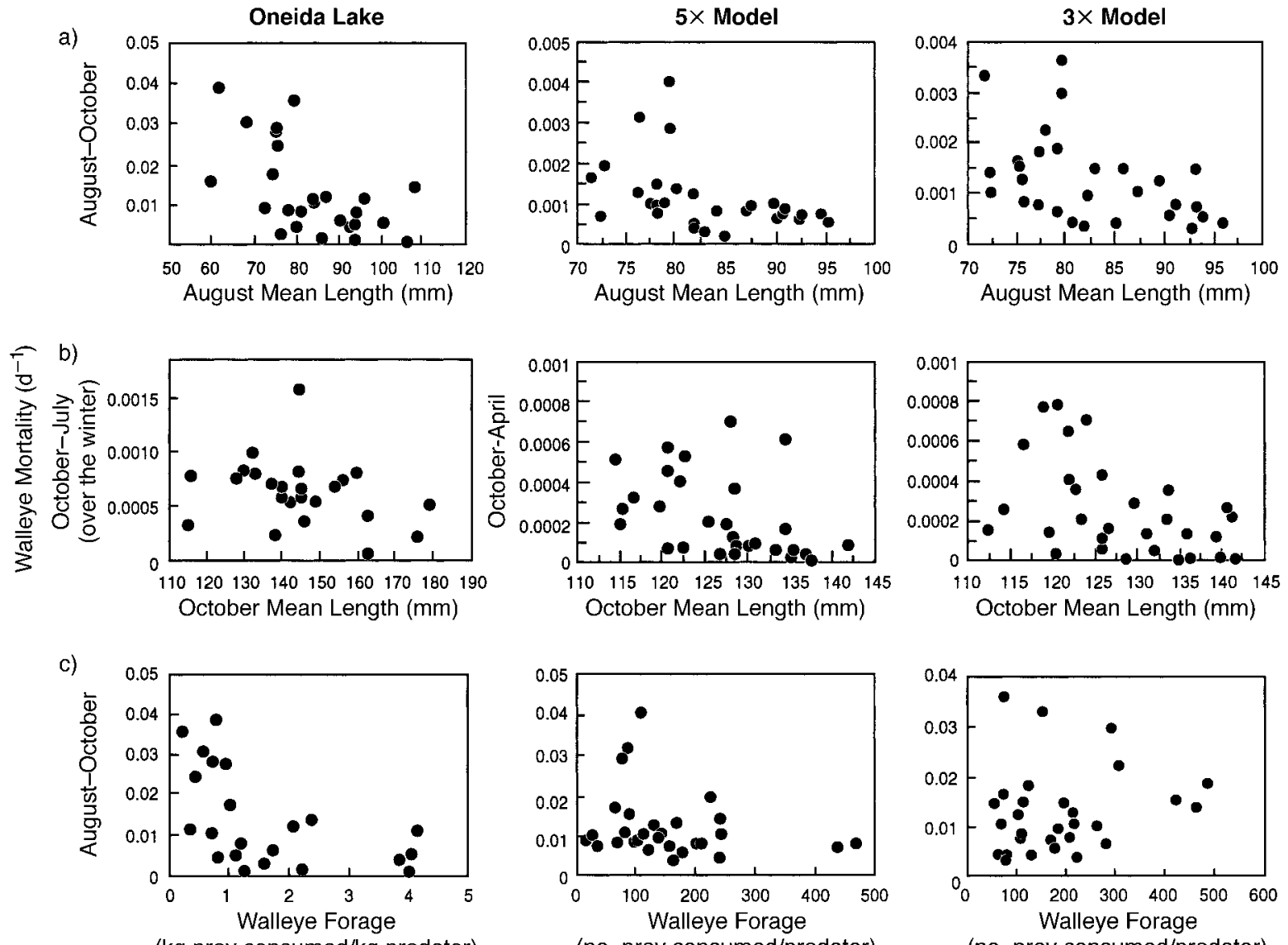

FIG. 7. Predicted and observed YOY relationships between walleye mortality rates and mean lengths and walleye forage. Predicted relationships are from years $25-55$ of the $3 \times$ and $5 \times$ corroboration simulations. Note that predicted and observed values are not plotted on the same $x$ - and $y$-scales, since we wish to emphasize the comparison of patterns rather than magnitudes. (a) Walleye mean August-October mortality rate vs. walleye mean length in August, (b) walleye mean mortality rate for the period October-July of the next year vs. walleye mean length in October, and (c) walleye mean August-October mortality rate vs. forage (forage fish and YOY and yearling yellow perch and walleye) available to walleye. Note that walleye forage is expressed differently between Oneida Lake and model values.

\section{Predator-prey dynamics}

Model simulations showed that yellow perch and walleye responses to increased alternative walleye prey were complex. Predicted responses depended on both the magnitude of increased walleye prey and the type of prey. Walleye abundances exhibited less variation under both increased mayfly and forage fish densities, whereas yellow perch abundances exhibited less variation for small increases in mayflies only. Yellow perch recruitment generally increased under increased mayfly densities, but decreased under increased forage fish densities. Walleye recruitment increased for increased forage fish densities but not for large increases in mayfly densities. The only consistent result was that walleye populations were relatively stabilized by increased alternative prey.

Some consequences of increased walleye prey predicted by the model were unanticipated. We did not expect increased forage fish densities to cause longer young adults, but shorter older adult, walleye. Also surprising was that high increases in mayfly densities eventually resulted in no increase in walleye recruitment, because longer yearling walleye reduced the YOY yellow perch available for adult walleye. Perhaps the empirical data indicating lower recruitment under increased forage fish (Table 1) were not counter-intuitive after all!

Without the increased benthos densities component of high mayflies, predicted responses were more consistent with the increased stability and the increased recruitment hypotheses. Simulating the high mayfly period involved increasing benthos densities, reducing fishing mortality, and reducing adult consumption of fish, which made interpretation of model responses nonsimplistic. We performed an additional simulation in which we eliminated fishing mortality on walleye and did not allow adult yellow perch or walleye consumption of fish during 5 June-19 July of each year as before, while maintaining benthos at baseline densities. Predicted CVs of abundances were lower than 
FIG. 8. Annual abundances (no. individuals/ ha) of adult (a) yellow perch ( $\geq$ age- 3 ) and (b) walleye ( $\geq$ age-4) in May under baseline conditions, with stocking (line with open circles) and without walleye stocking (solid line).

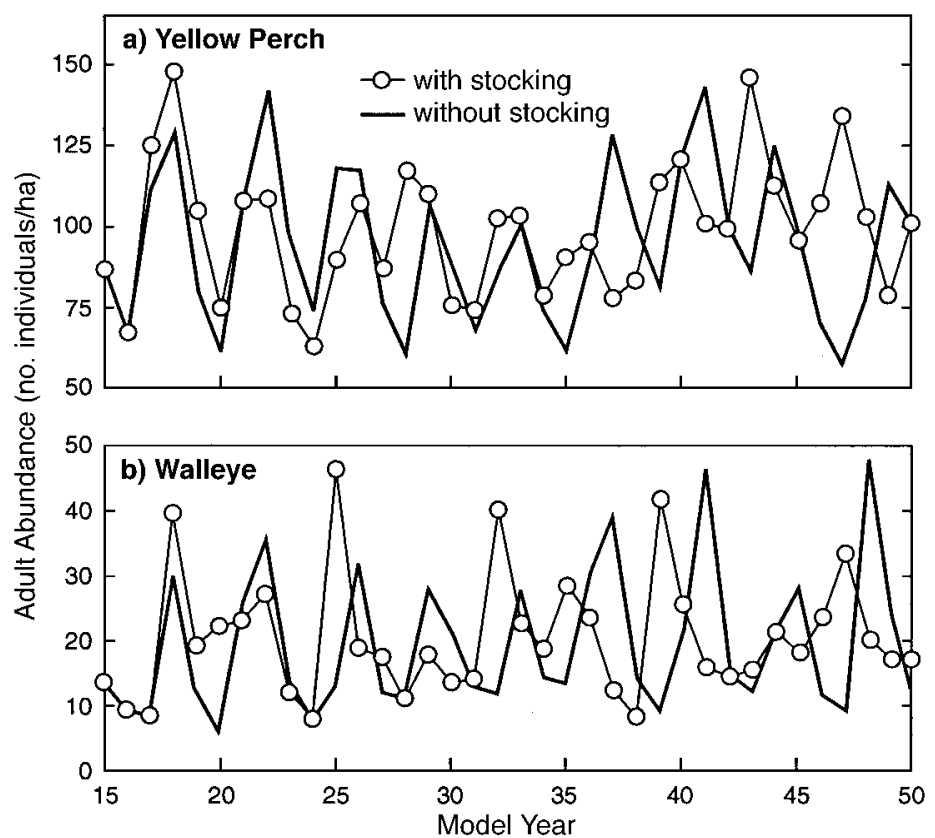

baseline for yellow perch YOY abundance in October ( $27 \%$ vs. $44 \%$ ), recruitment (30\% vs. $58 \%$ ) and adult abundances ( $21 \%$ vs. $27 \%$ ), and for walleye YOY abundance in October (55\% vs. $96 \%$ ), recruitment (49\% vs. $89 \%$ ), and adult abundances (41\% vs. $67 \%$ ). In addition, predicted recruitment was higher for yellow perch (386 individuals/ha vs. 210 individuals/ha) and for walleye (49 individuals/ha vs. 34 individuals/ha). The fact that no increase and small increases in benthos densities tended to be consistent with the increased stability and recruitment hypotheses suggests that the buffering effects of mayflies were more important to the observed response in Oneida Lake than any direct stimulation of growth. In contrast, Johnson (1977) and
FIG. 9. Predicted coefficients of variation of annual YOY abundance in October, recruitment, and adult abundances of $(\mathrm{a}-\mathrm{c})$ yellow perch and (d-f) walleye for baseline, increased $(2 \times, 3 \times$, $4 \times, 5 \times)$ mayflies, and increased $(3 \times, 5 \times, 7 \times)$ forage fish simulations.
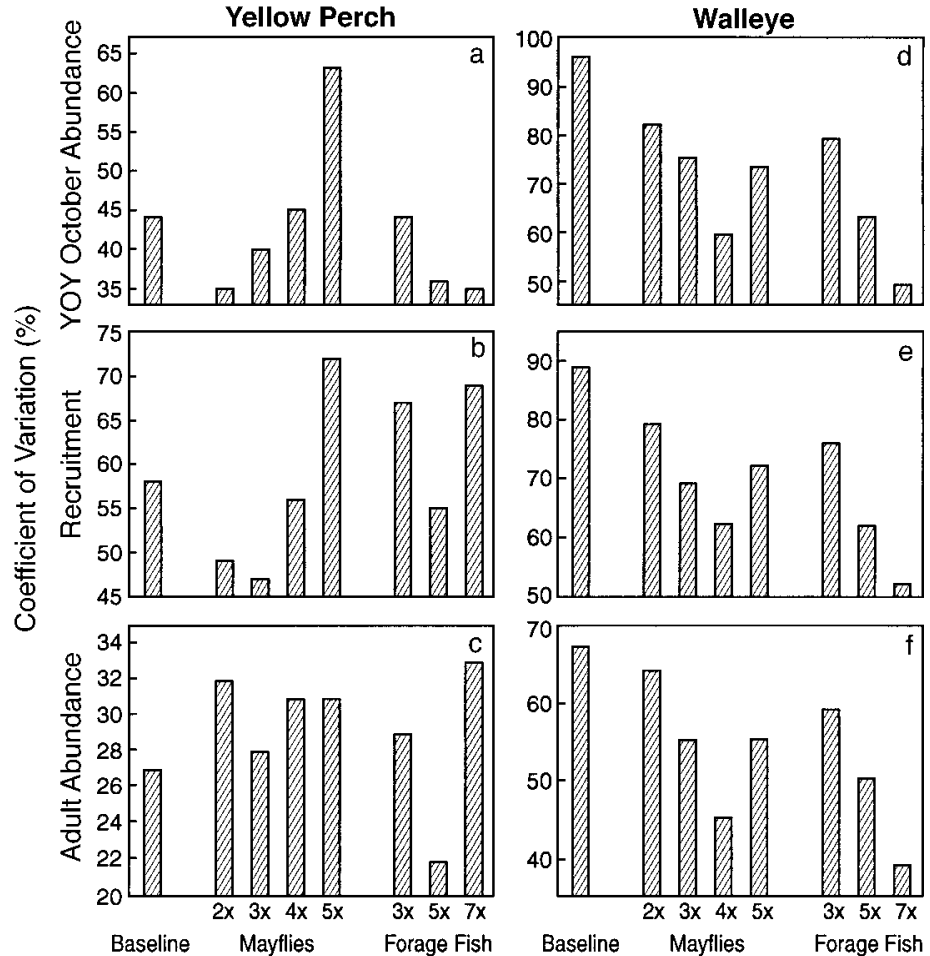
TABLE 5. Simulated responses of yellow perch to increased $(2 \times, 3 \times, 4 \times, 5 \times)$ mayfly densities. Effects are stated as changes from baseline to increased mayfly densities. Results were used to evaluate and explain the hypothesis that increased mayflies would cause higher recruitment.

\begin{tabular}{|c|c|c|c|c|c|c|}
\hline \multirow[b]{2}{*}{ Effect } & \multirow[b]{2}{*}{ Unit } & \multicolumn{5}{|c|}{ Model prediction } \\
\hline & & Baseline & $2 \times$ & $3 \times$ & $4 \times$ & $5 \times$ \\
\hline $\begin{array}{l}\text { Increased } 18 \mathrm{~mm} \text { to August } \\
\text { survival }\end{array}$ & percent & 34 & 43 & 43 & 45 & 42 \\
\hline Higher YOY August abundance & no. individuals/ha & 10428 & 15575 & 17376 & 18941 & 19584 \\
\hline Shorter YOY October mean length & $\mathrm{mm}$ & 62.9 & 56.6 & 56.4 & 53.5 & 51.1 \\
\hline $\begin{array}{l}\text { Decreased YOY August-October } \\
\text { survival }\end{array}$ & percent & 35 & 25 & 21 & 14 & 13 \\
\hline Lower YOY October abundance & no. individuals/ha & 3598 & 3823 & 3596 & 2592 & 2367 \\
\hline $\begin{array}{l}\text { Increased YOY October to } \\
\text { recruitment survival }\end{array}$ & percent & 7 & 10 & 11 & 19 & 18 \\
\hline Higher recruitment & no. individuals/ha & 210 & 380 & 379 & 493 & 425 \\
\hline Higher adult abundance & no. individuals/ha & 106 & 142 & 142 & 173 & 168 \\
\hline Faster (slightly) adult growth & mm/yr (age-4) & 20.9 & 20.8 & 22.2 & 23.4 & 25.5 \\
\hline Similar adult mean lengths & $\mathrm{mm}($ age-4) & 215 & 210 & 215 & 213 & 212 \\
\hline Similar maturation & percent (age-4) & 41 & 32 & 38 & 36 & 45 \\
\hline Similar fecundity & no. eggs/spawner & 30313 & 28395 & 29201 & 27730 & 29089 \\
\hline More spawners & no. individuals/ha & 35.4 & 43.7 & 47.5 & 54.1 & 57.4 \\
\hline Increased egg production & no. eggs/ha $\left(\times 10^{-6}\right)$ & 1.11 & 1.20 & 1.35 & 1.48 & 1.65 \\
\hline Higher $18 \mathrm{~mm}$ abundance & no. individuals/ha & 30329 & 36413 & 40670 & 42328 & 46938 \\
\hline
\end{tabular}

Hayes et al. (1992) found that increased benthos (by reduction of benthivorous white sucker, Catostomus commersoni, abundances) resulted in increased consumption of mayflies and increased growth of yellow perch. Thus, the increased growth effect from increased benthos densities was important to model responses, but its role in Oneida Lake is debatable.

Our results can be viewed in the context of the classical approach to predator-prey dynamics. Murdoch and Bence (1987) concluded in a review paper on predator effects on prey in aquatic systems that: (1) predators likely act to destabilize prey populations, and (2) surprisingly little progress has been made on predatorprey stability, despite 50 or more years of research. As part of this second conclusion, Murdoch and Bence were optimistic that new developments, such as sizestructured modeling, will help illuminate predator-prey issues. The model used herein is an example of such a modeling approach. It is much richer in biological detail than past approaches, and represents a more complex and realistic predator-prey situation.

Our example deals with numerical and developmental responses of predators, rather than the functional responses that have been the focus of much of predatorprey research. Murdoch and Bence (1987) dismiss numerical responses, because the longer generation times of the predator introduces time lags into their responses, which are destabilizing. They also dismiss developmental responses given that most predators grow slowly, relative to the fluctuations in their prey, and utilize multiple prey types that buffer the effects of variation in individual prey species. Murdoch and Bence (1987) then focus on functional responses as potentially stabilizing, but conclude they are likely destabilizing in aquatic systems. Recently, Beisner et al. (1997) used a laboratory system in which the predator
(Mesostoma ehrenbergii) and prey (Daphnia) have similar generation times, to show that numerical response of the predator can have a destabilizing effect on its prey. In our modeled system, numerical and developmental responses were dominant. Numerical responses were possible because yellow perch and walleye have similar generation times, increased alternative prey was sustained for all years in the simulation, and model simulations spanned multiple generations. Representation of the full life cycles of both species also permitted complex developmental responses. For example, increased mayflies resulted in longer walleye recruits (Table 6), which increased predation mortality on YOY yellow perch (Table 5). However, walleye recruits got so large and consumed so much YOY yellow perch under $5 \times$ mayflies, that adult walleye growth rates became reduced and ultimately led to lowered walleye egg production and increased cannibalism. Model results showed that complex numerical and developmental responses consistently led to increased stability of the predator population (walleye), but that the response of the prey population (yellow perch) was mixed.

Our results show that alternative prey caused increased density dependence in yellow perch, but that this increase in density dependence was not necessarily related to increased stability. The classical approach to assessing whether the predator would cause increased stability of the prey population is to determine if predator responses cause density-dependent mortality of the prey (Murdoch and Bence 1987). In our multiyear simulations, the analogous comparison would be whether prey population stability was related to the degree of density dependence. We used the $2 \times, 3 \times, 4 \times$, and $5 \times$ mayflies simulations to illustrate our results. Prey population stability was computed as the $\mathrm{CV}$ of annual 
TABLE 6. Simulated responses of walleye to increased $(2 \times, 3 \times, 4 \times, 5 \times)$ mayfly densities. Effects are stated as changes from baseline to increased mayfly densities. Results were used to evaluate and explain the hypothesis that increased mayflies would cause increased recruitment.

\begin{tabular}{|c|c|c|c|c|c|c|}
\hline \multirow[b]{2}{*}{ Effect } & \multirow[b]{2}{*}{ Unit } & \multicolumn{5}{|c|}{ Model prediction } \\
\hline & & Baseline & $2 \times$ & $3 \times$ & $4 \times$ & $5 \times$ \\
\hline Longer recruits & $\mathrm{mm}$ & 242 & 254 & 266 & 276 & 285 \\
\hline \multirow{2}{*}{ Slower adult growth } & mm/yr (age-5) & 46.5 & 44.9 & 38.1 & 26.4 & 25.3 \\
\hline & (age-10) & 39.1 & 35.8 & 33.8 & 30.3 & 30.0 \\
\hline \multirow{2}{*}{ Shorter adult mean lengths } & $\mathrm{mm}($ age -5$)$ & 387 & 367 & 364 & 363 & 356 \\
\hline & (age-10) & 635 & 576 & 560 & 524 & 508 \\
\hline Older maturation & percent (age-5) & 36 & 24 & 26 & 22 & 28 \\
\hline Fewer spawners & no. individuals/ha & 6.7 & 4.1 & 3.8 & 2.3 & 2.8 \\
\hline Decreased egg production & no. eggs/ha $\left(\times 10^{-5}\right)$ & 3.31 & 2.61 & 2.41 & 1.54 & 1.59 \\
\hline Lower $9 \mathrm{~mm}$ abundance & no. individuals/ha & 685 & 514 & 550 & 324 & 363 \\
\hline \multirow[t]{2}{*}{ Reduced cannibalism } & g YOY $\cdot$ adult $^{-1} \cdot \mathrm{d}^{-1}$ & 0.22 & 0.21 & 0.18 & 0.12 & 0.13 \\
\hline & $\mathrm{g}$ yearling $\cdot$ adult ${ }^{-1} \cdot \mathrm{d}^{-1}$ & 0.64 & 0.69 & 0.43 & 0.17 & 0.16 \\
\hline $\begin{array}{l}\text { Increased } 9 \mathrm{~mm} \text { to } \\
\text { recruitment survival }\end{array}$ & percent & 6.5 & 13.1 & 11.9 & 13.8 & 12.0 \\
\hline $\begin{array}{l}\text { Higher recruitment for } 2 \times \text { and } \\
3 \times \text { but similar recruitment } \\
\text { for } 4 \times \text { and } 5 \times\end{array}$ & no. individuals/ha & 34 & 50 & 43 & 34 & 32 \\
\hline $\begin{array}{l}\text { Higher adult abundance for } \\
2 \times \text { and } 3 \times \text { but similar adult } \\
\text { abundance for } 4 \times \text { and } 5 \times\end{array}$ & no. individuals/ha & 17.9 & 28.3 & 25.0 & 19.2 & 18.8 \\
\hline $\begin{array}{l}\text { Higher yield for } 2 \times \text { and } 3 \times \\
\text { but similar for } 4 \times \text { and } 5 \times\end{array}$ & no. individuals/ha & 13.5 & 19.1 & 17.4 & 13.2 & 13.1 \\
\hline $\begin{array}{l}\text { Higher (slightly) yield in kg/ } \\
\text { ha at } 2 \times \text { and } 3 \times \text { but lower } \\
\text { for } 4 \times \text { and } 5 \times\end{array}$ & $\mathrm{kg} / \mathrm{ha}$ & 9.0 & 10.1 & 9.6 & 6.5 & 6.4 \\
\hline
\end{tabular}

abundances. The degree of density dependence was quantified for each simulation by the magnitude of the negative slope and the $R^{2}$ of the regression of the 35 annual values (years 15-50) of life stage survival on the number entering the life stage. The higher the $R^{2}$ and the absolute magnitude of the negative slope, the greater the degree of density dependence. These analyses were performed for yellow perch for $18 \mathrm{~mm}-\mathrm{Oc}$ tober (YOY) survival and for October-October of the next year (yearling) survival. We present the results from a linear regression model $\left(y=\beta_{0}+\beta_{1} x\right)$; similar results were also obtained with an exponential model $\left(y=\beta_{0} e^{-\beta_{1} x}\right)$. Increased mayflies resulted in slopes that are more negative and higher $R^{2}$ for YOY yellow perch survival compared to baseline (Fig. 10a), but slopes that are less negative and lower $R^{2}$ for yearling survival compared to baseline (Fig. 10b). The degree of density dependence was not related to stability for either the YOY or yearling survival. Numerical and developmental responses of walleye resulted in increased YOY

TABLE 7. Simulated responses of yellow perch to increased $(3 \times, 5 \times, 7 \times)$ forage fish densities. Effects are stated as changes from baseline to increased forage fish densities. Results were used to evaluate and explain the hypothesis that increased forage fish would cause increased recruitment.

\begin{tabular}{|c|c|c|c|c|c|}
\hline \multirow[b]{2}{*}{ Effect } & \multirow[b]{2}{*}{ Unit } & \multicolumn{4}{|c|}{ Model prediction } \\
\hline & & Baseline & $3 \times$ & $5 \times$ & $7 \times$ \\
\hline \multicolumn{6}{|l|}{ Decreased $18 \mathrm{~mm}$ to } \\
\hline \multirow[t]{2}{*}{ Lower YOY abundances } & no. individuals/ha (August) & 10428 & 10416 & 9156 & 8874 \\
\hline & no. individuals/ha (October) & 3598 & 3315 & 2658 & 2405 \\
\hline Lower recruitment & no. individuals/ha & 210 & 147 & 98 & 80 \\
\hline \multicolumn{6}{|l|}{ Longer YOY October } \\
\hline \multicolumn{6}{|l|}{ Longer recruit mean } \\
\hline length & $\mathrm{mm}$ & 147 & 149 & 163 & 155 \\
\hline Similar adult growth & $\mathrm{mm} / \mathrm{yr}$ (age-4) & 20.9 & 21.7 & 22.5 & 22.8 \\
\hline \multicolumn{6}{|l|}{ Longer adult mean } \\
\hline lengths & mm (age-4) & 215 & 218 & 223 & 226 \\
\hline Younger maturation & percent (age-4) & 41 & 48 & 58 & 63 \\
\hline Higher fecundity & no. eggs/spawner & 30313 & 38305 & 35692 & 37019 \\
\hline Lower adult abundance & no. individuals/ha & 106 & 83 & 68 & 60 \\
\hline Fewer spawners & no. individuals/ha & 35.4 & 30.8 & 28.8 & 28.0 \\
\hline Similar egg production & no. eggs/ha $\left(\times 10^{-6}\right)$ & 1.11 & 1.02 & 1.01 & 1.02 \\
\hline Similar $18 \mathrm{~mm}$ abundance & no. individuals/ha & 30329 & 30668 & 29784 & 29775 \\
\hline
\end{tabular}


TABLE 8. Simulated responses of walleye to increased $(3 \times, 5 \times, 7 \times)$ forage fish densities. Effects are stated as changes from baseline to increased forage fish densities. Results were used to evaluate and explain the hypothesis that increased forage fish would cause increased recruitment.

\begin{tabular}{|c|c|c|c|c|c|}
\hline \multirow[b]{2}{*}{ Effect } & \multirow[b]{2}{*}{ Unit } & \multicolumn{4}{|c|}{ Model prediction } \\
\hline & & Baseline & $3 \times$ & $5 \times$ & $7 \times$ \\
\hline Longer recruit mean length & $\mathrm{mm}$ & 242 & 266 & 279 & 288 \\
\hline \multirow{2}{*}{ Reduced cannibalism } & $\mathrm{g} \cdot$ individual $^{-1} \cdot \mathrm{d}^{-1}(\mathrm{YOY})$ & 0.22 & 0.20 & 0.16 & 0.17 \\
\hline & (yearling) & 0.64 & 0.54 & 0.22 & 0.18 \\
\hline $\begin{array}{l}\text { Higher (slightly) YOY August to } \\
\text { recruitment survival }\end{array}$ & percent & 76.9 & 76.9 & 82.9 & 83.9 \\
\hline Higher (slightly) recruitment & no. individuals/ha & 34 & 34 & 39 & 39 \\
\hline Higher adult abundance & no. individuals/ha & 17.9 & 18.3 & 20.6 & 20.7 \\
\hline Higher yield in number/ha & no. individuals/ha & 13.5 & 13.7 & 15.5 & 15.7 \\
\hline \multirow{2}{*}{ Slower adult growth } & $\mathrm{mm} / \mathrm{yr}($ age-5) & 46.5 & 45.7 & 35.3 & 36.7 \\
\hline & $\mathrm{mm} / \mathrm{yr}$ (age-10) & 36.6 & 32.1 & 21.8 & 19.4 \\
\hline Longer young adults & $\mathrm{mm}($ age-5) & 387 & 420 & 400 & 408 \\
\hline Younger maturation & percent (age-5) & 36 & 52 & 54 & 62 \\
\hline More spawners & no. individuals/ha & 6.7 & 6.9 & 8.0 & 9.3 \\
\hline Shorter older adults & $\mathrm{mm}($ age-10) & 635 & 614 & 538 & 540 \\
\hline Lower fecundity & no. eggs/spawner & 56835 & 46583 & 36972 & 25154 \\
\hline Similar egg production & no. eggs/ha $\left(\times 10^{-5}\right)$ & 3.31 & 3.21 & 2.97 & 3.29 \\
\hline Similar $9 \mathrm{~mm}$ abundance & no. individuals/ha & 685 & 699 & 628 & 760 \\
\hline $\begin{array}{l}\text { Similar YOY October } \\
\text { abundance }\end{array}$ & no. individuals/ha & 39 & 39 & 41 & 41 \\
\hline Similar yield & $\mathrm{kg} / \mathrm{ha}$ & 9.0 & 9.4 & 8.9 & 9.6 \\
\hline
\end{tabular}

yellow perch survival and decreased yearling yellow perch survival. Perhaps the link between density-dependent mortality and stability, based on relatively simple unstructured models, needs to be reevaluated in light of our results using a structured, multigenerational model.

\section{Density dependence}

Modeled walleye and yellow perch exhibited density-dependent survival, growth, and reproduction to compensate for changes in egg mortality rates. Simulations showed that both species ultimately produced fewer eggs under decreased egg mortality and more eggs under increased egg mortality conditions. Compensation in yellow perch was driven by changes in walleye predation on YOY yellow perch, which led to density-dependent yellow perch growth and maturation. Fewer yellow perch (increased egg mortality) led to fewer walleye, due to fewer years of high recruitment, and reduced predation pressure on YOY yellow perch. More yellow perch (decreased egg mortality) led to increased walleye growth and higher abundances, which resulted in increase predation on YOY yellow perch. Decreased walleye egg mortality ultimately led to increasing adult walleye mean lengths with increasing egg mortality. For walleye, longer adults resulted in younger maturation and increased fecundity that more than offset lower adult abundances, resulting in increasing spawners and egg production with increasing egg mortality rate. Similar density-dependent changes in survival, growth, and maturation have been reported for yellow perch and walleye in other systems

TABLE 9. Simulated responses of yellow perch to decreased and increased egg mortality rate. Effects are stated as changes with increasing egg mortality. Results were used to evaluate and explain the hypothesis that density-dependent growth and survival resulted in compensation.

\begin{tabular}{|c|c|c|c|c|}
\hline \multirow[b]{2}{*}{ Effect } & \multirow[b]{2}{*}{ Unit } & \multicolumn{3}{|c|}{ Model prediction } \\
\hline & & $\begin{array}{l}\text { Decreased } \\
\text { mortality }\end{array}$ & Baseline & $\begin{array}{l}\text { Increased } \\
\text { mortality }\end{array}$ \\
\hline Increasing egg mortality & percent & 71 & 90 & 96 \\
\hline Lower total number of first feeders & no. individuals/ha & 178325 & 85036 & 40894 \\
\hline Lower $18 \mathrm{~mm}$ abundance & no. individuals/ha & 60594 & 30329 & 15325 \\
\hline \multicolumn{5}{|l|}{ Increased $18 \mathrm{~mm}$ to recruitment } \\
\hline survival & percent & 0.41 & 0.85 & 1.56 \\
\hline Higher (slightly) recruitment & no. individuals/ha & 205 & 210 & 221 \\
\hline Longer recruit mean length & $\mathrm{mm}$ & 141.8 & 144.5 & 151.8 \\
\hline Faster adult growth & $\mathrm{mm} / \mathrm{yr}$ (age-4) & 18.5 & 20.9 & 22.0 \\
\hline Longer adult mean lengths & $\mathrm{mm}($ age-4) & 205 & 215 & 221 \\
\hline Younger maturation & percent (age-4) & 24 & 41 & 54 \\
\hline Higher (slightly) fecundity & no. eggs/spawner & 27885 & 30313 & 30989 \\
\hline Similar adult abundance & no. individuals/ha & 103 & 106 & 112 \\
\hline More spawners & no. individuals/ha & 29.1 & 35.4 & 44.2 \\
\hline Higher egg production & no. eggs/ha $\left(\times 10^{-6}\right)$ & 0.80 & 1.11 & 1.35 \\
\hline
\end{tabular}


TABLE 10. Simulated responses of walleye to decreased and increased egg mortality rate. Effects are stated as changes with increasing egg mortality. Results were used to evaluate and explain the hypothesis that density-dependent growth and survival resulted in compensation.

\begin{tabular}{|c|c|c|c|c|}
\hline \multirow[b]{2}{*}{ Effect } & \multirow[b]{2}{*}{ Unit } & \multicolumn{3}{|c|}{ Model prediction } \\
\hline & & $\begin{array}{c}\text { Decreased } \\
\text { mortality }\end{array}$ & Baseline & $\begin{array}{l}\text { Increased } \\
\text { mortality }\end{array}$ \\
\hline Increasing egg mortality & percent & 78.0 & 95.5 & 97.5 \\
\hline Lower total number of first feeders & no. individuals/ha & 86655 & 35356 & 27307 \\
\hline Lower $9 \mathrm{~mm}$ abundance & no. individuals/ha & 2178 & 685 & 469 \\
\hline Increased $9 \mathrm{~mm}$ to YOY August survival & percent & 5.9 & 8.5 & 10.5 \\
\hline Lower recruitment & no. individuals/ha & 48 & 34 & 25 \\
\hline Lower adult abundance & no. individuals/ha & 25.5 & 17.9 & 13.3 \\
\hline Similar recruit mean length & $\mathrm{mm}$ & 244 & 242 & 237 \\
\hline \multirow[t]{2}{*}{ Faster adult growth } & $\mathrm{mm} / \mathrm{yr}($ age-5) & 42.7 & 46.5 & 83.1 \\
\hline & $\mathrm{mm} / \mathrm{yr}($ age-6) & 38.9 & 63.3 & 82.4 \\
\hline \multirow[t]{2}{*}{ Longer adult mean lengths } & $\mathrm{mm}($ age-5) & 387 & 387 & 480 \\
\hline & $\mathrm{mm}$ (age-6) & 424 & 451 & 561 \\
\hline Lower yield & no. individuals/ha & 19.7 & 13.5 & 11.4 \\
\hline Higher (slightly) yield in $\mathrm{kg} / \mathrm{ha}$ & $\mathrm{kg} / \mathrm{ha}$ & 8.6 & 9.0 & 9.9 \\
\hline \multirow[t]{2}{*}{ Younger maturation } & percent (age-5) & 32 & 36 & 58 \\
\hline & percent (age-6) & 43 & 58 & 88 \\
\hline More spawners & no. individuals/ha & 3.3 & 6.7 & 7.2 \\
\hline $\begin{array}{l}\text { Higher mean fecundity for } \\
\text { increased mortality }\end{array}$ & no. eggs/spawner & 62127 & 56835 & 80307 \\
\hline Higher egg production & no. eggs/ha $\left(\times 10^{-5}\right)$ & 2.01 & 3.31 & 5.43 \\
\hline
\end{tabular}

(see Saila et al. 1987). For example, Muth and Wolfert (1986) reported that a 3-fold increase in the walleye stock in western Lake Erie during the years 1976-1983 resulted in shorter mean lengths of age- 2 females and a drop from $90 \%$ to $7 \%$ in the percent mature of age2 females. In other studies, European perch in Windermere exhibited density-dependent growth (Le Cren et al. 1972). Over a 41-yr period, density-dependent growth caused the age of first reproduction to drop from 3 to $2 \mathrm{yr}$ and fecundity to increase by $46 \%$. This led to a 6 -fold variation in spawning biomass resulting in only a 2-fold variation in egg production (Craig and Kipling 1983).

Density-dependent growth, survival, and reproduction emerged from the size-based interactions implicit in model simulations. Growth and survival process formulations were not explicitly specified as density-dependent. We purposely avoided forcing density-dependent relationships into the model to allow us to assess the compensatory response attributable to variation in growth and predation. Fecundity and maturation responses are due to changes in growth rates and sizes at age. Fecundity and maturation also could be explicitly density-dependent, if individuals changed how they allocate energy in response to their condition (Henderson et al. 1996, Van Winkle et al. 1996). Adult mortality of both species also could have been specified as explicitly density-dependent. Lloyd (1996) reported a noisy, but significant, relationship between age-specific survival rates and adult abundances for Oneida Lake yellow perch. Also, we assumed all $\geq$ age- 4 walleye were vulnerable to the fishery. In actuality, under current management practices in Oneida Lake, walleye size limits in Oneida Lake can change annually depending on adult walleye abundances and projected future contributions of subadults (Forney 1980). Using size limits that change from year to year could confound interpretation of growth and YOY and yearling survival responses. Size limits are designed to change each year to protect the walleye stock and, thus, would result in compensatory fishing mortality. Use of true size-based, rather than age-based, fishery limits in model simulations would cause depensatory fishing mortality. Low walleye abundances would lead to long walleye and increased fishing pressure that would further reduce walleye abundances.

\section{Model weaknesses}

We opted to represent prey consumption in terms of biomass rather than calories. We recognize that caloric densities of prey and predator differ and that these differences can be important in determining fish growth. Zooplankton and benthos have lower caloric densities than adult fish (Hewett and Johnson 1992), and yellow perch and walleye caloric densities increase with size and peak in the summer to fall in Oneida Lake (Tarby 1977; B. Lantry, unpublished data). To determine the potential bias introduced by not tracking caloric dynamics of predators and prey, we implemented caloric adjustments into our yellow perch-walleye model. The following changes were made: (1) assigned fixed caloric densities for each prey type and for larvae, juveniles, and adults of yellow perch and walleye; (2) set prey densities to upper values observed in the historical data; (3) increased maximum consumption of adults; and (4) adjusted the biomass of each prey type consumed by multiplying by the ratio of prey to predator caloric values. These changes were necessary to provide enough caloric-adjusted food for growth, while still maintaining realistic prey densities. 

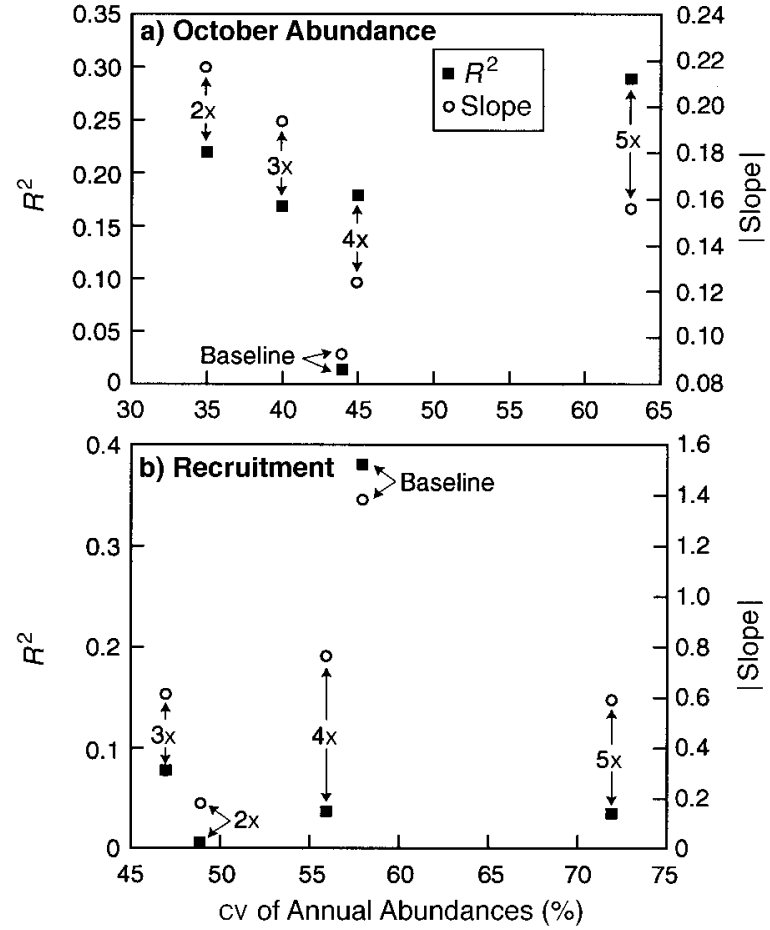

FIG. 10. Magnitude of the negative slope and $R^{2}$ vs. the coefficient of variation (CV) of annual abundances. The slope and $R^{2}$ are from the regression of the 35 annual values (years 15-50) of life stage survival on the number entering the life stage for yellow perch for the baseline, $2 \times, 3 \times, 4 \times$, and $5 \times$ mayflies simulations. The $\mathrm{CV}$ is computed based on the 35 annual values of the number surviving to end of the life stage. The higher the $R^{2}$ and the absolute magnitude of the negative slope, the greater is the degree of density dependence. The plots show results for (a) $18 \mathrm{~mm}$ to October (YOY) surviva vs. CV of October abundance, and (b) YOY October to October of the next year (yearling) survival vs. CV of yearling abundance in October (recruitment).

Model dynamics with the adjustment for calories were less realistic than the dynamics of the original (biomass-based) model. We recalibrated the model in the same manner as the original version of the model (adjustment of $K$ values and larval mortality rates). Predicted average adult abundances under baseline conditions were similar for the caloric-adjusted and original versions of the model for yellow perch $(95.4$ adults/ha vs. 114.0 adults/ha) and for walleye (19.9 adults/ha vs. 17.4 adults/ha). Predicted mean lengths at age for caloric-adjusted and original versions also were reasonably similar (e.g., age-4 yellow perch were $212 \mathrm{~mm}$ vs. $216 \mathrm{~mm}$; age-5 walleye were $327 \mathrm{~mm}$ vs. $365 \mathrm{~mm}$ ). However, the caloric-adjusted version generated unrealistically high interannual variation in adult abundances of yellow perch $(\mathrm{CV}=82 \%$ vs. $25 \%$ in the original version) and walleye ( $\mathrm{CV}=95 \%$ vs. $57 \%$ in the original version). Yellow perch and walleye exhibited predator-prey cycles with peaks roughly every 10 $\mathrm{yr}$ (rather than every $5 \mathrm{yr}$ as in the original version). Furthermore, the caloric-adjusted version had the same discrepancies with observed values as the original version (over-winter mortality of yellow perch increasing with fall length, YOY walleye August-October survival lower than observed, and walleye adult mean lengths more variable than observed). Why the caloricadjusted version generated more variable and longer period predator-prey cycles is not clear. With complex models such as the yellow perch-walleye model, calibration is subjective, and, thus, it is always possible that a set of parameter values could exist that would result in different, and perhaps more realistic, model dynamics than those obtained. We decided to use the biomass-based version of the model, because its performance was more similar to observed dynamics. Measurement of caloric changes in Oneida Lake biota is ongoing (B. Lantry, unpublished data), and further investigation of the dynamics of the calorio-adjusted version of the model is warranted.

Some caution is appropriate in interpreting predicted effects of increased walleye prey and compensation. While model dynamics under increased prey and changed egg mortality rates are qualitatively realistic, predicted magnitudes of changes are more uncertain. Yearling walleye relied heavily on benthos, so the model may overestimate the growth benefits of increased mayfly densities. Walleye adult mean lengths varied more than observed, and, thus, predicted changes in fecundity and maturation may be too large. Lack of the appropriate size dependence in yellow perch over-winter mortality could underestimate the effects of densitydependent YOY perch growth. Differences between mayflies and forage fish effects arise partly from differences in how their increases were imposed. While fishing and yellow perch mortality are undoubtedly reduced during mayfly outbreaks in Oneida Lake, our assumption of zero mortality may be an overestimate.

\section{Knowledge gaps}

Major discrepancies between predicted and observed values are of particular interest, as they suggest areas for further investigation. Four major differences between predicted and observed values were apparent: (1) over-winter mortality of yellow perch, (2) YOY August-October survival rate of walleye, (3) importance of benthos to yearling walleye diets, and (4) interannual variation of mean lengths of adult walleye.

Predicted yellow perch over-winter mortality was too low (Fig. 3b) and, contrary to the observed inverse relationship between fall length and over-winter mortality rate, predicted over-winter mortality rate increased with increasing fall mean length (Fig. 6b). Probability of YOY yellow perch surviving over-winter temperatures has also been shown to increase with length in laboratory and field situations (Post and Evans 1989). In model simulations, over-winter mortality was strongly influenced by the depensatory mortality appropriate for the summer but not the winter. In the absence of the depensatory mortality, the model is ca- 
pable of generating the expected size dependence of over-winter mortality. Jaworska et al. (1997) reported the results of simulations in which walleye were removed and their predation mortality on yellow perch was replaced by a constant daily rate. Increasing the metabolic rate of YOY yellow perch led to smaller yellow perch in October and higher over-winter mortality. Because predation mortality was a fixed rate, the only possible reason mortality would increase with decreasing yellow perch length is due to bioenergetics causing starvation (i.e., fish too thin for their length). These results imply that either the model overestimates the influence of walleye on yellow perch during the winter or that the bioenergetics predicted under low temperatures are not extreme enough to cause the expected over-winter mortality patterns. Field data on walleye consumption rates and the spatial distributions of walleye and yellow perch during the winter could help determine if the model overestimates the importance of walleye predation to over-winter survival of YOY yellow perch. Johnson and Evans (1990) found that winter temperatures caused juvenile yellow perch to change their swimming and feeding behavior. Additional laboratory and field studies of yellow perch lipid dynamics, behavior, and bioenergetics at low temperatures would enable more realistic simulation of their over-winter mortality.

Discrepancies between model simulations and observed values involving YOY and yearling walleye included over prediction of YOY August-October survival rate (Fig. 3e) and yearling walleye eating too much benthos relative to fish (Fig. 4). The only source of mortality simulated on YOY juvenile walleye is cannibalism. Whether predation mortality on YOY from species other than walleye adults, such as northern pike (Esox lucius) and smallmouth bass (Micropterus dolomieu), can account for the difference between simulated and observed YOY walleye survival rates is unlikely, but it cannot be dismissed. Increasing walleye cannibalism in model simulations by lowering the adult walleye $K$ values for YOY walleye as prey resulted in unrealistically low adult walleye abundances. Forcing yearling walleye to consume more YOY yellow perch and forage fish and less benthos resulted in small adult walleye. One possible explanation is the assumption of a single, well-mixed box, implying that all yearling and adult walleye effectively experience all YOY yellow perch and walleye. Whether spatial heterogeneity enables pockets of YOY yellow perch and walleye to avoid encountering adult walleye predators is not known. Post and McQueen (1988) concluded that inshore-offshore movements of larval and juvenile yellow perch were not attributable to prey abundances or predation risk. Measurement of the spatial distribution and overlap of different life stages of yellow perch and walleye in Oneida Lake has recently been investigated in detail (Scheuerell 1996) and should aid in further model refinement.
Another difference between simulated and observed values was that predicted internannual variation in adult walleye mean lengths was much greater than observed (Fig. 3f). Model-predicted variation in walleye mean lengths at age is large but still biologically possible. Mean length of age-5 walleye varied from $\sim 300$ $500 \mathrm{~mm}$ in corroboration simulations and from 290$671 \mathrm{~mm}$ across systems in southern Canada and the U.S. (Colby et al. 1979). Mean length of age-4 walleye varied from $\sim 350-500 \mathrm{~mm}$ in Western Lake Erie during 1947-1963, a period of dramatic decline in the walleye stock (Shuter and Koonce 1977). Variation in walleye mean lengths is important for generating density-dependent fecundity and maturation responses in model simulations and in other systems (Saila et al. 1987). Model-predicted daily consumption and growth rates of adult walleye, and interannual variation in the length of the growing season, were reasonable, when compared to observed dynamics in Oneida Lake. One possible explanation for predicted walleye adult lengths being too variable is that model simulations utilized a single length-mass relationship for all years. All modeled fish increase their length as they gain mass. The model ignores the influences of season, age, condition, and reproduction on how walleye adults allocate surplus energy to their mass, length, and lipid content. Empirical data from Oneida lake have shown substantial variation in adult walleye condition, reflecting differences in the length to mass relationship among years, and an uncoupling of length from mass related to spawning and the allocation of energy to reproductive products. Determining why observed mean lengths at age in Oneida Lake vary less than predicted would help us better understand the compensatory responses of walleye in Oneida Lake and improve model predictions by better simulating interannual variation in adult walleye mean lengths.

The Oneida Lake database offers an excellent opportunity for developing realistic predator-prey models, predicting the effects of perturbations on predatorprey dynamics, and better understanding compensation. The seemingly simple predator-prey system of Oneida Lake becomes quite complex upon detailed analysis. We hope that our individual-based modeling analysis of the walleye-yellow perch interaction in Oneida Lake has raised more questions than it has answered. Continued biological monitoring of Oneida Lake, and ongoing and future special studies stimulated by the modeling analysis, will permit further testing of model predictions and improve our understanding of walleye-yellow perch population dynamics in Oneida Lake and other systems. Examination of short-term pulses in alternative prey and transient model responses would also be fruitful. We think our approach of using a detailed, structured model based on a well-studied system holds promise. Such models can be used to complement and check predator-prey paradigms based on simple, theoretical models, and they can lead to 
more realistic representations of density dependence in population models.

\section{ACKNOWLEDGMENTS}

We wish to thank Lars Rudstam and Russ Lloyd for sharing their data and insights on percid dynamics in Oneida Lake. Tom Miller and Jim Rice provided excellent comments on earlier versions that greatly improved the manuscript. Research sponsored by the Electric Power Research Institute under contract RP2932-2 (DOE No. ERD-87-672) with the U.S. Department of Energy, under contract DE-AC0596OR22464 with Lockheed Martin Energy Research Corp. This is Publication No. 4794 of the Environmental Sciences Division, ORNL, and No. 184 of the Cornell University Biological Field Station.

\section{Literature Cited}

Barnthouse, L. W., J. Boreman, S. W. Christensen, C. P. Goodyear, W. Van Winkle, and D. S. Vaughan. 1984. Population biology in the courtroom: the Hudson River controversy. BioScience 34:14-19.

Beddington, J. R., C. A. Free, and J. H. Lawton. 1976. Concepts of stability and resilience in predator-prey models. Journal of Animal Ecology 45:791-816.

Beisner, B. E., E. McCauley, and F. J. Wrona. 1997. Predatorprey instability: individual-level mechanisms for population-level results. Functional Ecology 11:112-120.

Berg, M. B., and R. A. Hellenthal. 1991. Secondary production of Chrionomidae (Diptera) in a north temperate stream. Freshwater Biology 25:497-505.

Berryman, A. A. 1992. The origins and evolution of predator-prey theory. Ecology 73:1530-1535.

Beyer, J. E. 1989. Recruitment stability and survival—simple size-specific theory with examples from the early life dynamics of marine fish. Dana 7:45-147.

Buijse, A. D., and R. P. Houthuijzen. 1992. Piscivory, growth, and size-selective mortality of age-0 pikeperch (Stizostedion lucioperca). Canadian Journal of Fisheries and Aquatic Sciences 49:894-902.

Cacela, D. A. 1989. Recruitment dynamics of white perch (Morone americana) in Oneida Lake, New York, 19601985. Thesis. Cornell University, Ithaca, New York, USA.

Campbell, E. A. 1989. Laboratory examination of size-selective predation by small walleye (Stizostedion vitreum) on yellow perch (Perca flavescens). Thesis. University of Wisconsin, Madison, Wisconsin, USA.

Chevalier, J. R. 1973. Cannibalism as a factor in first-year survival of walleyes in Oneida Lake. Transactions of the American Fisheries Society 103:739-744.

Clady, M. D. 1976. Influence of temperature and wind on the survival of early stages of yellow perch, Perca flaves cens. Journal of the Fisheries Research Board of Canada 33: $1887-1893$

Clady, M. D., and B. Hutchinson. 1975. Effect of high winds on eggs of yellow perch, Perca flavescens, in Oneida Lake. Transactions of the American Fisheries Society 104:524525.

Clady, M. D., and B. Hutchinson. 1976. Food of the yellow perch, Perca flavescens, following a decline of the burrowing mayfly Hexagenia limbata. Ohio Journal of Science 76 : 133-138.

Colby, P. J., R. E. McNicol, and R. A. Ryder. 1979. Synopsis of biological data on the walleye Stizostedion vitreum vitreum (Mitchill 1818). FAO Fisheries Synopsis 119, Food and Agricultural Organization of the United Nations, Rome, Italy.

Craig, J. F. 1987. The biology of perch and related fish Timber Press, Portland, Oregon, USA.

Craig, J. F., and C. Kipling. 1983. Reproduction effort vs. the environment: case histories of Windermere perch, Perca fluviatilis L., and pike, Esox lucius L. Journal of Fish Biology 22:713-727.

den Boer, P. J., and J. Reddingius. 1989. On the stabilization of animal numbers. Problems of testing 2. Confrontation with data from the field. Oecologia 79:143-149.

Ebenman, B., and L. Persson. 1988. Size-structured populations. Springer-Verlag, New York, New York, USA.

Eberhardt, L. L. 1970. Correlation, regression, and density dependence. Ecology 51:306-310.

Edgar, G., and C. Shaw. 1995. The production and trophic ecology of shallow-water fish assemblages in southern Australia. I. Species richness, size-structure and production of fishes in Western Port, Victoria. Journal of Experimental Marine Biology and Ecology 194:53-81.

Forney, J. L. 1965. Factors affecting growth and maturity in a walleye population. New York Fish and Game Journal 12:217-232.

-1967. Estimates of biomass and mortality rates in a walleye population. New York Fish and Game Journal 14: 176-192.

- 1971. Development of dominant year classes in a yellow perch population. Transactions of the American Fisheries Society 100:739-749.

- 1974. Interactions between yellow perch abundance, walleye predation, and survival of alternate prey in Oneida Lake, New York. Transactions of the American Fisheries Society 104:15-24.

- 1976. Year-class formation in the walleye (Stizostedion vitreum vitreum) population of Oneida Lake, New York, 1966-73. Journal of the Fisheries Research Board of Canada 33:783-792.

- 1977a. Evidence for interspecific and intraspecific competition as factors regulating walleye (Stizostedion vitreum vitreum) biomass in Oneida Lake, New York. Journal of the Fisheries Research Board of Canada 34:1812-1820. - 1977b. Reconstruction of yellow perch (Perca flavescens) cohorts from examination of walleye (Stizostedion vitreum vitreum) stomachs. Journal of the Fisheries Research Board of Canada 34:925-932.

- $1977 c$. Dynamics of a walleye-yellow perch predator-prey association in Oneida Lake: relation of forage fish abundance to utilization by walleye. New York Department of Environmental Conservation, Report for Project No. F-17-R, Cornell University Biological Field Station, Bridgeport, New York, USA.

1978. Dynamics of a walleye-yellow perch predator-prey association in Oneida Lake: analysis of year-class formation in a walleye population. New York Department of Environmental Conservation, Final Report for Project No. F-17-R, Cornell University Biological Field Station, Bridgeport, New York, USA.

- 1980. Evolution of a management strategy for the walleye in Oneida Lake, New York. New York Fish and Game Journal 27:105-141.

Fox, M. G. 1991. Food consumption and bioenergetics of young-of-the-year walleye (Stizostedion vitreum vitreum): model predictions and population density effects. Canadian Journal of Fisheries and Aquatic Sciences 48:434-441.

Grosslein, M. D. 1961. Estimation of angler harvest on Oneida Lake. Dissertation. Cornell University, Ithaca, New York, USA.

Hastings, A., and T. Powell. 1991. Chaos in a three-species food chain. Ecology 72:896-903.

Hayes, D. B., W. M. Taylor, and J. C. Schneider. 1992. Response of yellow perch and the benthic invertebrate community to a reduction in the abundance of white suckers. Transactions of the American Fisheries Society 121:36-53.

Henderson, B. A., J. L. Wong, and S. J. Nepszy. 1996. Reproduction of walleye in Lake Erie: allocation of energy. 
Canadian Journal of Fisheries and Aquatic Sciences 53: 127-133.

Hewett, S. W., and B. L. Johnson. 1992. Fish bioenergetics model 2: a generalized bioenergetics model of fish growth for microcomputers. University of Wisconsin Sea Grant Technical Report No. WIS-SG-92-250, Madison, Wiscon$\sin$, USA.

Hokanson, K. E. F., and C. F. Kleiner. 1974. Effects of constant and rising temperatures on survival and developmental rates of embryonic and larval yellow perch, Perca flavescens. Pages 437-448 in J. H. S. Blaxter, editor. Early life history of fish, Springer-Verlag, New York, New York, USA.

Hokanson, K. E. F., and G. J. Lien 1986. Effects of diet on growth and survival of larval walleyes. Progressive FishCulturist 48:250-258.

Holling, C. S. 1965. The functional response of predators to prey density and its role in mimicry and population regulations. Memoirs of the Entomological Society of Canada Number 45, Ontario, Canada.

Houde, E. D. 1969. Distribution of larval walleyes and yellow perch in a bay of Oneida Lake and its relation to water currents and zooplankton. New York Fish and Game Journal 16:184-205.

Jacobsen, T. V. 1966. Trends in abundance of the mayfly (Hexagenia limbata) and chironomids in Oneida Lake. New York Fish and Game Journal 13:168-175.

Jaworska, J. S., K. A. Rose, and L. W. Barnthouse. 1997. General response patterns of fish populations to stress: an evaluation using an individual-based simulation model. Journal of Aquatic Ecosystem Stress and Recovery 6:1531.

Johnson, F. H. 1977. Responses of walleye (Stizostedion vitreum vitreum) and yellow perch (Perca flavescens) populations to removal of white sucker (Catostomus commersoni) from a Minnesota Lake, 1966. Journal of the Fisheries Research Board of Canada 34:1633-1642.

Johnson, T. B., and D. O. Evans. 1990. Behaviour, energetics, and associated mortality of young-of-the-year white perch (Morone americana) and yellow perch (Perca flavescens) under simulated winter conditions. Canadian Journal of Fisheries and Aquatic Sciences 48:672-680.

Johnston, T. A., M. K. Friesen, J. A. Mathias, and K. D. Rowes. 1992. Zooplankton dynamics and walleye (Stizostedion vitreum) production in culture ponds at Methley Beach (Dauphin Lake), Manitoba: 1985-1989. Canadian Technical Report of Fisheries and Aquatic Sciences 1841, Winnipeg, Manitoba, Canada.

Knight, R. L., F. J. Margraf, and R. F. Carline. 1984. Piscivory by walleyes and yellow perch in western Lake Erie. Transactions of the American Fisheries Society 113:677693.

Knight, R. L., and B. Vondracek. 1993. Changes in prey fish populations in western Lake Erie, 1969-1988, as related to walleye, Stizostedion vitreum, predation. Canadian Journal of Fisheries and Aquatic Sciences 50:1289-1298.

Krebs, C. J. 1991. The experimental paradigm and long-term population studies. IBIS 133 (Supplement 1):3-8.

Lake, J. S. 1967. Rearing experiments with five species of Australian freshwater fishes. 1. Inducement to spawning. Australian Journal of Marine and Freshwater Research 18: 137-153.

Le Cren, E. D., C. Kipling, and J. C. McCormack. 1972. Windermere: effects of exploitation and euthrophication on the salomind community. Journal of the Fisheries Research Board of Canada 29:819-832.

Li, S., and J. A. Mathias. 1982. Causes of high mortality among cultured larval walleyes. Transactions of the American Fisheries Society 111:710-721.

Lindegaard, C. 1989. A review of secondary production of zoobenthos in freshwater ecosystems with special reference to Chironomidae (Diptera). Acta Biologica Debrecina Oecologica Hungarica 3:231-240.

Lloyd. R. C. 1996. Evaluation of management alternatives for the walleye-yellow perch fishery in Oneida Lake, New York. Dissertation, Cornell University, Ithaca, New York, USA.

Madon, S. P., and D. A. Culver. 1993. Bioenergetics model for young-of-the-year walleye: an in situ approach using experimental ponds. Transactions of the American Fisheries Society 122:797-813.

Mansueti, A. J. 1964. Early development of the yellow perch, Perca flavescens. Chesapeake Science 5:46-66.

Mathias, J. A., and S. Li. 1982. Feeding habits of walleye larvae and juveniles: comparative laboratory and field studies. Transactions of the American Fisheries Society 111: $722-735$.

Matsuda, H., K. Kawasaki, N. Shigesada, E. Teramoto, and L. M. Ricciardi. 1986. Switching effect on the stability of the prey-predator system with three trophic levels. Journal of Theoretical Biology 122:251-262.

McElman, J. F., and E. K. Balon. 1979. Early ontogeny of walleye, Stizostedion vitreum vitreum, with saltatory development. Environmental Biology of Fishes 4:309-348.

Miller, T. J., L. B. Crowder, J. A. Rice, and E. A. Marschall. 1988. Larval size and recruitment mechanisms in fishes: toward a conceptual framework. Canadian Journal of Fisheries and Aquatic Sciences 45:1657-1670.

Mills, E. L., J. L. Confer, and R. C. Ready. 1984. Prey selection by young yellow perch: the influence of capture success, visual acuity, and prey choice. Transactions of the American Fisheries Society 113:579-587.

Mills, E. L., and J. L. Forney. 1981. Energetics, food consumption, and growth of young yellow perch in Oneida Lake, New York. Transactions of the American Fisheries Society 110:479-488.

Mills, E. L., and J. L. Forney 1983. Impact on Daphnia pulex of predation by young yellow perch in Oneida Lake, New York. Transactions of the American Fisheries Society 112: 154-161.

Mills, E. L., and J. L. Forney. 1988. Trophic dynamics and development of freshwater pelagic food webs. Pages 1130 in S. R. Carpenter, editor. Complex interactions in lake communities. Springer-Verlag, New York, New York, USA.

Mills, E. L. J. L. Forney, M. D. Clady, and W. R. Schaffner. 1978. Oneida Lake. Pages 367-451 in J. A. Bloomfield, editor. Lakes of New York State, Volume II, Academic Press, New York, New York, USA.

Mills, E. L., J. L. Forney, and K. J. Wagner. 1987. Fish predation and its cascading effect on the Oneida Lake food chain. Pages 118-131 in W. C. Kerfoot and A. Sih, editors. Predation: direct and indirect impacts on aquatic communities. University Press of New England, Hanover, New Hampshire, USA.

Mills, E. L., M. V. Pol, R. E. Sherman, and T. E. Culver. 1989. Interrelationships between prey body size and growth of age-0 yellow perch. Transactions of the American Fisheries Society 118:1-10.

Minton, J. W., and R. B. McLean. 1982. Measurements of growth and consumption of sauger (Stizostedion canadense): implication for fish energetics studies. Canadian Journal of Fisheries and Aquatic Sciences 39:1396-1403.

Murdoch, W. W., and J. Bence. 1987. General predators and unstable prey populations. Pages 17-30 in W. C. Kerfoot and A. Sih, editors. Predation: direct and indirect impacts on aquatic communities. University Press of New England, Hanover, New Hampshire, USA.

Murdoch, W. W., and A. Oaten. 1975. Predation and population stability. Advances in Ecological Research 9:1-131. 
Murray, B. G. 1994. On density dependence. Oikos 69:520523.

Muth, K. M., and D. R. Wolfert. 1986. Changes in growth and maturity of walleyes with stock rehabilitation in Western Lake Erie. North American Journal of Fisheries Management 6:168-175.

Nielson, L. A. 1980. Effect of walleye (Stizostedion vitreum vitreum) predation on juvenile mortality and recruitment of yellow perch (Perca flavescens) in Oneida Lake, New York. Canadian Journal of Fisheries and Aquatic Sciences 37:1119.

Noble, R. L. 1968. Mortality rates of pelagic fry of yellow perch, Perca flavescens (Mitchill), in Oneida Lake, New York, and an analysis of the sampling problem. Dissertation. Cornell University, Ithaca, New York, USA.

1972. Mortality rates of walleye fry in a bay of Oneida Lake, New York. Transactions of the American Fisheries Society 101:720-723.

Oaten, A., and W. W. Murdoch. 1975a. Functional response and stability in predator-prey systems. American Naturalist 109:289-298.

Oaten, A., and W. W. Murdoch. 1975b. Switching, functional response, and stability in predator-prey systems. American Naturalist 109:299-318.

Pepin, P., and R. A. Meyers. 1991. Significance of egg and larval size to recruitment variability of temperate marine fish. Canadian Journal of Fisheries and Aquatic Sciences 48: $1820-1828$

Persson, L. 1988. Asymmetries in competitive and predatory interactions in fish populations. Pages 203-218 in B. Ebenman and L. Persson, editors. Size-structured populations. Springer-Verlag, New York, New York, USA.

Post, J. R. 1990. Metabolic allometry of larval and juvenile yellow perch (Perca flavescens): in situ estimates and bioenergetic models. Canadian Journal of Fisheries and Aquatic Sciences 47:554-560.

Post, J. R., and D. O. Evans. 1989. Size-dependent overwinter mortality of young-of-the-year yellow perch (Perca flavescens): laboratory, in situ enclosure, and field experiments. Canadian Journal of Fisheries and Aquatic Sciences 46: $1958-1968$

Post, J. R., and D. J. McQueen. 1988. Ontogenetic changes in the distribution of larval and juvenile yellow perch $(\mathrm{Per}$ ca flavescens): a response to prey or predators? Canadian Journal of Fisheries and Aquatic Sciences 45:1820-1826.

Post, J. R., and L. G. Rudstam. 1992. Fisheries management and the interactive dynamics of walleye and perch populations. Pages 381-406 in J. F. Kitchell, editor. Food web management: a case study of Lake Mendota. Springer-Verlag, New York, New York, USA.

Prajneshu, and P. Holgate. 1987. A prey-predator model with switching effect. Journal of Theoretical Biology 125:6166.

Prout, M. W., E. L. Mills, and J. L. Forney. 1990. Diet, growth, and potential competitive interactions between age-0 white perch and yellow perch in Oneida Lake, New York. Transactions of the American Fisheries Society 119: 966-975.

Rose, K. A., S. W. Christensen, and D. L. DeAngelis. 1993. Individual-based modeling of populations with high mortality: a new method based on following a fixed number of model individuals. Ecological Modelling 68:273-292.

Rose, K. A., J. A. Tyler, D. SinghDermot, and E. S. Rutherford. 1996. Multispecies modeling of fish populations. Pages 194-222 in B. A. Megrey and E. Moksness, editors.
Computers in fisheries research. Chapman and Hall, New York, New York, USA.

Roseman, E. F., E. L. Mills, J. L. Forney, and L. G. Rudstam. 1996. Evaluation of competition between age-0 yellow perch (Perca flavescens) and gizzard shad (Dorosoma cepedianum) in Oneida Lake, New York. Canadian Journal of Fisheries and Aquatic Sciences 53:865-874.

Saila, S. B., X. Chen, K. Erizini, and B. Martin. 1987. Compensatory mechanisms in fish populations. Volume 1. Critical evaluation of case histories of fish populations experiencing chronic exploitation or impact. Electric Power Research Institute Report EA-5200, Palo Alto, California, USA.

Scheffer, M., J. M. Baveci, D. L. DeAngelis, K. A. Rose, and E. H. van Nes. 1995. Super-individuals a simple solution for modeling large populations on an individual basis. Ecological Modelling 80:161-170.

Scheuerell, M. D. 1996. Spatial dynamics of fish populations: implications for predator-prey interactions in Oneida Lake, New York. Thesis. Cornell University, Ithaca, New York, USA.

Serns, S. L. 1982. Influence of various factors on density and growth of age-0 walleyes in Escanaba Lake, Wisconsin, 1958-1980. Transactions of the American Fisheries Society 111:299-306.

Shuter, B. J., and K. K. Ing. 1997. Factors affecting the production of zooplankton in lakes. Canadian Journal of Fisheries and Aquatic Sciences 54:359-377.

Shuter, B. J., and J. F. Koonce. 1977. A dynamic model of the western Lake Erie walleye (Stizostedion vitreum vitreum) population. Journal of the Fisheries Research Board of Canada 34:1972-1982.

Slade, N. A., 1977. Statistical detection of density dependence from a series of sequential censuses. Ecology 58: 1094-1102.

Strong, D. R. 1986. Density-vague population change. Trends in Ecology and Evolution 1:39-42.

Swift, D. R. 1965. Effect of temperature on mortality and rate of development of the eggs of the pike (Esox lucius L.) and the perch (Perca fluciatilis L.). Nature 206:528.

Tarby, M. L. 1974. Characteristics of yellow perch cannibalism in Oneida Lake and the relation to first year survival. Transactions of the American Fisheries Society 103:462471.

1977. Energetics and growth of walleye (Stizostedion vitreum vitreum) in Oneida Lake, New York. Dissertation. Cornell Univerisity, Ithaca, New York, USA.

Tarby, M. L., and J. L. Forney. 1978. Dynamics of a walleyeyellow perch predator-prey association in Oneida Lake: analysis of year-class formation in a yellow perch population. New York Department of Environmental Conservation, Final Report for Project No. F-17-R, Cornell University Biological Field Station, Bridgeport, New York, USA.

Thorpe, J. 1977. Synopsis of biological data on the perch Perca fluviatilis Linnaeus, 1758 and Perca flavescens Mitchill, 1814. FAO Fisheries Synopsis 113, Food and Agricultural Organization of the United Nations, Rome, Italy.

Treasurer, J. W. 1983. Estimates of egg and viable embryo production in a lacustrine perch, Perca fluviatilis. Environmental Biology of Fishes 8:3-16.

Van Winkle, W., B. D. Holcomb, H. I. Jager, J. A. Tyler, S. Whitaker, and B. J. Shuter. 1996. Regulation of energy aquisition and allocation to respiration, growth, and reproduction: conceptual framework and example using rainbow trout. Pages 126-178 in R. C. Chambers and E. A. Trippel, editors. Early life history and recruitment in fish populations. Chapman and Hall, New York, New York, USA. 